\title{
Influence of carbon on the mechanical behavior and microstructure evolution of CoCrFeMnNi processed by high pressure torsion
} \author{
Yulia Ivanisenko ${ }^{\text {a }}$ \\ ${ }^{a}$ Institute of Nanotechnology, Karlsruhe Institute of Technology, Karlsruhe 76021, Germany \\ ${ }^{\mathrm{b}}$ Institute of Solid State Physics, Russian Academy of Sciences, Chernogolovka 142432, Russian Federation \\ c Institute for Applied Materials, Karlsruhe Institute of Technology, Karlsruhe 76021, Germany \\ ${ }^{\mathrm{d}}$ Laboratory of Bulk Nanostructured Materials, Belgorod State University, Belgorod 308015, Russian Federation \\ e Department of Materials Physics, Eötvös Loránd University, Budapest, PO Box 32, Budapest 1518, Hungary \\ ${ }_{\mathrm{f}}^{\mathrm{f}}$ Department of Materials Science and Engineering, University of California Irvine, Irvine, United States
}

Yemao Lu ${ }^{\mathrm{a}, *}$, Andrey Mazilkin ${ }^{\mathrm{a}, \mathrm{b}}$, Torben Boll ${ }^{\mathrm{c}}$, Nikita Stepanov ${ }^{\mathrm{d}}$, Sergei Zherebtzov ${ }^{\mathrm{d}}$, Gennady Salishchev ${ }^{\mathrm{d}}$, Éva Ódor ${ }^{\mathrm{e}}$, Tamas Ungar ${ }^{\mathrm{e}}$, Enrique Lavernia ${ }^{\mathrm{f}}$, Horst Hahn ${ }^{\mathrm{a}, \mathrm{f}}$,

\section{A R T I C L E I N F O}

\section{Keywords:}

High entropy alloys

Severe plastic deformation

Carbon segregation

Mechanical properties

Grain refinement

Fracture mechanism

\begin{abstract}
A B S T R A C T
In this study, a Cantor type high entropy alloys with the addition of $\mathrm{C}$ interstitials (, $0,0.5$ and 2 at.\%) were processed via high pressure torsion (HPT) under $6.5 \mathrm{GPa}$ by $0.5,1$ and 3 turns at room temperature. The microstructures and mechanical properties of samples before and following HPT were investigated. In all compositions studied, HPT deformation led to a dramatic grain size refinement down to a nanoscale range and also resulted in a considerable increase in dislocation density. Atom Probe Tomography studies reveal that in the alloy with 2 at.\% C, C atoms segregated at the boundaries of the nano-grains. The hardness of specimens with $0,0.5$ and $2 \%$ at. C approached a maximum value at a plateau at $490 \mathrm{HV}, 550 \mathrm{HV}$ and $640 \mathrm{HV}$, respectively. This plateau was reached at an HPT shear strain corresponding to more than $\sim 20$. The yield and ultimate tensile strength values of the as-cast alloys increased with increasing $\mathrm{C}$ content. The uniform elongation of all three alloys studied exceeded $30 \%$. The yield strength values of the HPT processed samples increased significantly and reached 1.7 GPa, $1.9 \mathrm{GPa}$ and $2.4 \mathrm{GPa}$, respectively, with $0,0.5$ and 2 at.\% C; however, a dramatic decrease of ductility was observed. Analysis of the factors contributing to the strengthening of HPT processed alloys revealed that the conventional approach based on dislocation motion resulted in significantly overestimated yield stress values in comparison with the experimentally obtained ones. It was proposed that the discrepancy between the theoretical estimate and experimental results is related to the emergence of grain boundary sliding. The present results provide new insights on the leverage of strength versus ductility by combining HPT processing with alloying with an interstitial-type element.
\end{abstract}

\section{Introduction}

The so-called Cantor alloy (equiatomic CoCrFeNiMn), one of high entropy alloys (HEAs) with a single face-centered cubic (fcc) phase, has attracted increased attention in the past decade largely because of its excellent mechanical properties [1-10]. The most remarkable feature of this alloy is the superior combination of ductility and strength at cryogenic temperatures in comparison with that at room temperature, especially in a fine-grained state $[2,11,12]$. However, even with the mean grain size as small as $\sim 1 \mu \mathrm{m}$, the alloy still shows a rather low yield strength of around $700 \mathrm{MPa}$ with a uniform elongation of $\sim 42 \%[10]$. Commonly, the fcc-structured Cantor alloy system shows much higher

\footnotetext{
* Corresponding author.

E-mail address: yemao.lu@partner.kit.edu (Y. Lu).
}

ductility but lower strength when compared with other HEA systems, for instance bcc HEAs [13]. This has been attributed to a dissimilarity of crystalline structures having different slip systems and by the contribution of twinning deformation that is also known as the dynamic Hall-Petch effect [5].

One approach that has been implemented to increase the strength of the Cantor alloys is to incorporate interstitial-type elements (e.g., C) into the fcc HEAs, yielding notable improvements in strength at room temperature [14-18]. C dissolved in the matrix contributes to solid solution strengthening. In addition, at higher $\mathrm{C}$ concentrations the formation of carbides can provide precipitation strengthening $[15,19,20]$. In the ascast Cantor alloys, the carbides can be formed even at $\mathrm{C}$ concentration less than 0.1 at $\%[16,21]$, thereby limiting the solid solution strength- 
ening contribution. This effect is obviously associated with a high concentration of chromium, which is known to be a strong carbide forming element [18].

Severe plastic deformation (SPD) techniques can be used to obtain ultra-fine grained (UFG) microstructures in metallic alloys to achieve high strength [22]. High pressure torsion (HPT) is the most effective SPD method due to the high applied strain, which results in nanoscale crystals and exceptionally high strength [23]. The application of the SPD method to HEAs, especially to Cantor-type alloys, is one of the areas of research interest in the last few years. The grain size can be easily reduced under $100 \mathrm{~nm}$ and even down to $\sim 10 \mathrm{~nm}$ using HPT; in addition the hardness increased approximately three times, up to $\sim 500 \mathrm{HV}[24-$ 29], as compared with a coarse grain state. All these studies are based on single phase fcc alloys without the addition of interstitials, and only a few studies are related to the effects of interstitials on the mechanical behavior are available $[14,15,17,18,21,30-32]$.

HPT processing makes it possible, not only to refine the microstructure down to the nanoscale, but also to affect phase composition of the metallic alloys [33-35]. Depending on the material and the exact processing conditions, different effects can be observed, for example, dissolution or precipitation of secondary phases, formation of homogeneous solid solutions between naturally immiscible elements, segregation of elements at the grain boundaries (GBs), to name a few. Recently, chemical inhomogeneity has been found to strongly influence the mechanical properties of HEAs [36-38]. For instance, replacement of Mn by Pd in a Cantor type equiatomic alloy results in notably ( $\sim 1.5$ times) higher yield strength, maintaining similar strain hardening and ductility [39]. A significant improvement in mechanical properties due to the Pd addition was attributed to the formation of a characteristic fluctuation length of 1-3 nm that provided considerable resistance to dislocation glide. Due to its unique characteristics, HPT can potentially be a unique tool to tune the chemical homogeneity and mechanical properties of HEAs.

The current investigation was performed using three Cantor-type alloys with a reduced $\mathrm{Cr}$ content, and additions of $0,0.5$ and 2 at. $\%$ of $\mathrm{C}$, previously studied in coarse grained state in $[17,18,21]$, in order to reveal the influence of interstitial alloying on the microstructure development during HPT and the resulting mechanical properties. The amount of $\mathrm{Cr}$ in alloys was reduced in order to avoid the formation of chromium carbides and to increase the solubility of carbon in fcc lattice. According to the equilibrium phase diagrams for carbon-doped $\mathrm{CoCr}_{\mathrm{x}} \mathrm{FeMnNi}$ for several $\mathrm{Cr}$ concentrations [18], the solubility of carbon in the fcc solid solution increases along with a decrease in the $\mathrm{Cr}$ molar fraction from 1 to 0.25 . For example, the equiatomic CoCrFeMnNi alloy can dissolve only 0.36 at. $\%$ of $\mathrm{C}$ in the fcc solid solution at $1000{ }^{\circ} \mathrm{C}$, whereas the corresponding amount for the CoCr0.25FeMnNi alloy is 1.61 at.\% [18]. The microstructures, mechanical properties, and the mechanisms of strengthening and fracture were studied in the HPT processed alloys. Chemical homogeneity of the alloys before and after HPT was analyzed via atom probe tomography (APT), which is capable of detecting elemental spatial distributions, including that corresponding to $\mathrm{C}$ interstitial.

\section{Materials and experimental methods}

For the synthesis of non-equiatomic $\mathrm{Co}_{1} \mathrm{Cr}_{0.25} \mathrm{Fe}_{1} \mathrm{Mn}_{1} \mathrm{Ni}_{1}$ (subscripts indicate the molar fraction of the respective component) alloys with the reduced $\mathrm{Cr}$ content, high purity elements (99.9 wt.\%) were melted by vacuum induction with the addition of different amounts of $\mathrm{C}$. The nominal concentration of $\mathrm{C}$ in the alloys was $0,0.5$ and 2 at.\%. The chemical compositions of the as-melted alloys measured by energy dispersive $\mathrm{X}$-ray (EDX) for metallic elements and hot gas carrier method for $\mathrm{C}$ content. The corresponding results are shown in Table 1. Cylinders with the diameter of $15 \mathrm{~mm}$ were machined from the produced ingots. For the HPT processing, disks with the diameter of $15 \mathrm{~mm}$ and initial thickness of $0.7 \mathrm{~mm}$ were sectioned out. HPT was performed at room temperature under a hydrostatic pressure of $6.5 \mathrm{GPa}$ for $0.5,1$ and 3 turns with
Table 1

Chemical composition of the as-cast alloys (at.\%).

\begin{tabular}{lllllll}
\hline Nominal C content & $\mathrm{C}$ & $\mathrm{Cr}$ & $\mathrm{Co}$ & $\mathrm{Fe}$ & $\mathrm{Ni}$ & $\mathrm{Mn}$ \\
\hline 0 & 0.039 & 6.20 & 23.41 & 23.81 & 22.72 & 23.82 \\
0.5 & 0.540 & 6.25 & 23.33 & 23.33 & 22.93 & 23.62 \\
2 & 2.200 & 6.46 & 23.01 & 22.32 & 21.24 & 24.77 \\
\hline
\end{tabular}

the rotation speed of $0.5 \mathrm{rpm}$. Therefore, the specimens under the study were identified as $\mathrm{CxNy}$, where $\mathrm{x}$ means the nominal $\mathrm{C}$ content for each alloy and $y$ denotes the number of revolutions during HPT. The von Mises equivalent strain $(\varepsilon)$ is calculated as:

$\varepsilon=\frac{2 \pi N r}{\sqrt{3} h}$

Where $r$ is the radius of the considered position, $N$ is the number of revolutions and $h$ represents the thickness of the disk [23,40].

Zeiss LEO 1530 scanning electron microscope and Zeiss Auriga 60 with backscattered electron (BSE) and EDX detectors were used for microstructure characterization and elemental analysis for both HPT and as-cast specimens. Specimens for XRD analysis were prepared by mechanical polishing and final electro-polishing to remove the damaged surface layer. X-ray diffraction measurements were performed using a Philips X'Pert powder diffractometer with a $\mathrm{Cu}-\mathrm{K} \alpha$ anode. The strain and crystallite size were evaluated using a Convolutional Multiple Whole profile fitting (CMWP) [41] and the lattice parameters were evaluated by a X'Pert High Score software using a Rietveld analysis. Transmission electron microscopy (TEM, STEM) was carried out using FEI Tecnai F20-ST at $200 \mathrm{kV}$. TEM lamellae for TEM study and the tips for APT analysis were prepared on FEI Strata 400 and Zeiss Auriga 60 using Ga focused ion beam. APT measurements were conducted using CamecaLEAP $4000 \times \mathrm{HR}$ instrument in laser probe mode at $55 \mathrm{~K}$, with a pulse energy of $30 \mathrm{pJ}$, a pulse rate of $200 \mathrm{kHz}$ and a target detection rate of $0.3 \%$. The reconstruction of APT data was performed with IVAS 3.6.14 software.

Vickers micro-hardness was measured with a load of $500 \mathrm{~g}$ with a dwell time of $10 \mathrm{~s}$ on the polished surface of the samples using Buehler Micromet-5104 device. The distance between indents was maintained at a constant value of $0.5 \mathrm{~mm}$. Four series of measurements along the HPT disc diameters were conducted for each sample after HPT processing. For as-cast samples at least 10 points were measured. Tensile tests were performed at room temperature at a strain rate of $10^{-3} \mathrm{~s}^{-1}$ using a custom-built computer controlled micro-tensile stage equipped with a high-precision laser extensometer P-50 by Fiedler Optoelectronics. For precise elongation measurements, the specimens were marked with $\mathrm{TiO}_{2}$ paint using an airbrush. The tensile specimens were cut out from the HPT disks and as-cast ingots with a gauge length of $3 \mathrm{~mm}$ and a square cross-section of $\sim 0.6 \mathrm{~mm}^{2}$. At least two samples for each state were pulled to fracture to obtain statistically reliable results.

\section{Results}

\subsection{Microstructure observations}

\subsubsection{Microstructure of HEAs before HPT}

Typical backscattered electron images of the as-cast microstructures of the alloys with different $\mathrm{C}$ contents are shown in Fig. 1 (a - c). All samples are coarse grained; grains are typically several hundred microns in diameter. Fine inclusions (visible as dark spots in Fig. 1) noticed in all the alloys are oxides and sulfides reported previously in this alloy system [27,42]. Meanwhile, Fig. 1 likewise reveals that the alloys solidify with primary fcc dendrites and interdendritic segregation, which is prevalent in as-cast CoCrFeMnNi HEAs [1]. In the alloy with 2 at.\% $\mathrm{C}$, narrow lamellar precipitates along GBs are observed under a higher magnification Fig. 1(d). These precipitates in the earlier research [18] were identified as $\mathrm{M}_{7} \mathrm{C}_{3}$ type carbides. 


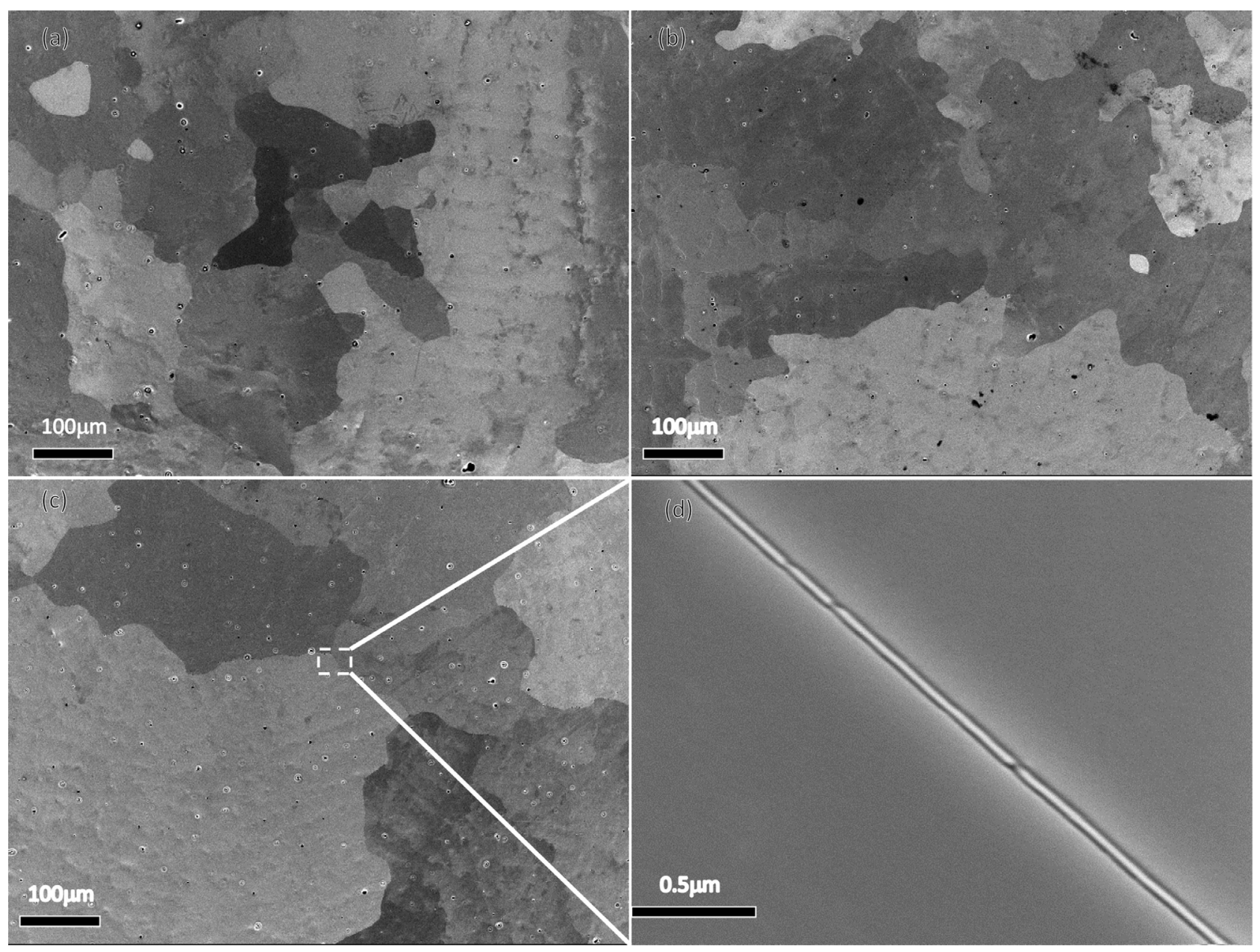

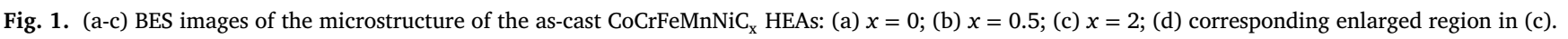

In order to reveal the composition of the carbides and their morphology, Fig. 2 shows a 3-dimensional reconstruction of the carbide on a grain boundary in the as-cast C2 alloy. The carbide enriched with $\mathrm{C}$ and $\mathrm{Cr}$ is seen in Fig. 2(a). Ni and Co are partitioned mainly in the fcc phase, while $\mathrm{Mn}$ and Fe are distributed more evenly between the fcc phase and the carbide particles. An interface view of the carbide and the matrix highlighted by iso-surfaces with the respective thresholds of 34 at.\% Cr, 28 at.\% Ni and 38at.\% Mn are shown in Fig. 2(b); the corresponding 1-dimensional composition profile across the carbide in Fig. 2(c), computed along the red arrow, is shown in Fig. 2(b). The carbide has a lamellar shape with a thickness of $\sim 25 \mathrm{~nm}$ and crosses the whole reconstruction volume.. Further, the $\mathrm{C}$ concentration measured within the carbide in Fig. 2(c) is $\sim 17$ at.\%, which does not fit the anticipated concentration in neither the $\mathrm{M}_{7} \mathrm{C}_{3}$ nor $\mathrm{M}_{23} \mathrm{C}_{6}$ type carbide. Thus, the chemical composition of the carbide is likely far from equilibrium. An increase of the $\mathrm{Cr}$ and $\mathrm{C}$ concentration from the interface towards the matrix suggests that the formation of the carbide leads to $\mathrm{Cr}$ and $\mathrm{C}$ depletion at the grain boundary, which indicates that such carbides precipitate after complete solidification of the alloy. The formation of $\mathrm{M}_{23} \mathrm{C}_{6}$ and $\mathrm{M}_{7} \mathrm{C}_{3}$ carbides with similar morphology has been frequently observed in some austenitic steels after ageing (see, for examples [4348]). It was established that the precipitates discontinuously form at high angle grain boundaries, and like all boundary precipitates have a parallel orientation with one of the grains. These precipitates grow further with preferential migration of incoherent $\mathrm{M}_{23} \mathrm{C}_{6} / \mathrm{fcc}$ matrix boundary and gradually became aggregated to form film-like precipitates. The thermodynamic aspects and mechanism of such carbides formation in Fe-Cr-Ni steels are discussed in Refs. [44-51].

\subsubsection{Microstructures of HPT processed alloys with different $C$ content}

It has been reported that high pressure torsion leads to the formation of a gradient microstructure varying along the radius, which is conditioned by the gradient distribution of shear strain (Eq. (1)) [24,29]. Fig. 3 shows the microstructure evolution in the CON0.5 alloy from the HPT sample center towards its periphery. In the central areas, the initial (as-cast) dendritic structure with the inhomogeneous distribution of constituting elements is persisting (Fig. 3a, d). At the radius of $0.25 \mathrm{~mm}$, which corresponds to a relatively small equivalent strain of $\sim 0.6$, massive twinning (or rather nano-twining) occurs as shown in Fig. 3(b), (c) suggests that a nano-structure formed apparently at the distance of $7 \mathrm{~mm}$ (equivalent strain of $\sim 4$ ). The sample surface shows almost uniform BSE contrast, nevertheless the elemental distributions in the matrix exhibit striped bands along the shear direction (Fig. 3(f)). The regions depleted with $\mathrm{Mn}$ and $\mathrm{Ni}$ are enriched in $\mathrm{Fe}, \mathrm{Cr}$ and $\mathrm{Co}$, and vice versa.

Fig. 4(a-c) show the TEM dark field images and corresponding selected area electron diffraction (SAED) patterns of the high entropy alloys, after three turns of HPT. All observations were performed in a cross section at the periphery of HPT disks. The microstructure of all the alloys is characterized by elongated in shear direction grains. Apparently, the grain size decreases with the $\mathrm{C}$ increasing content. Nano-twins and dislocations are clearly observed in the bright field images for C0.5N3 and C2N3 alloys shown in Fig. 4(d-e), respectively, however the relative amount of twins is not very high. In fact, less than $10 \%$ of grains contain twins. The ring arrangement of the diffraction spots suggests that the nano-structure contains boundaries of high-angle misorientation. The average grain sizes are 45, 29, and $17 \mathrm{~nm}$ in C0N3, C0.5N3, and C2N3 alloys, respectively, as determined using the linear intercept method on 
(a)
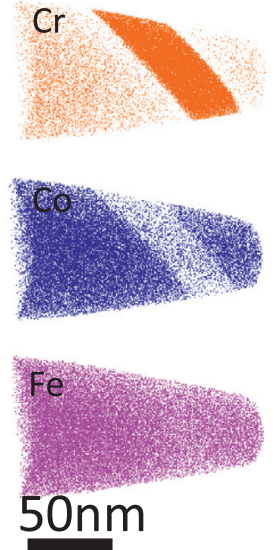
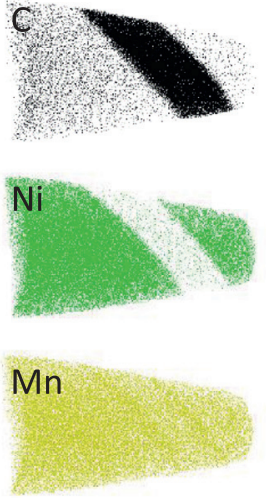

(b)

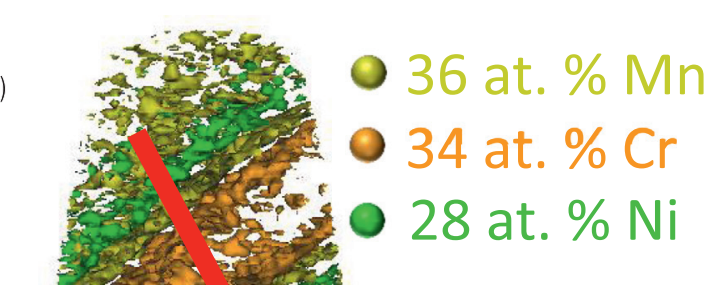

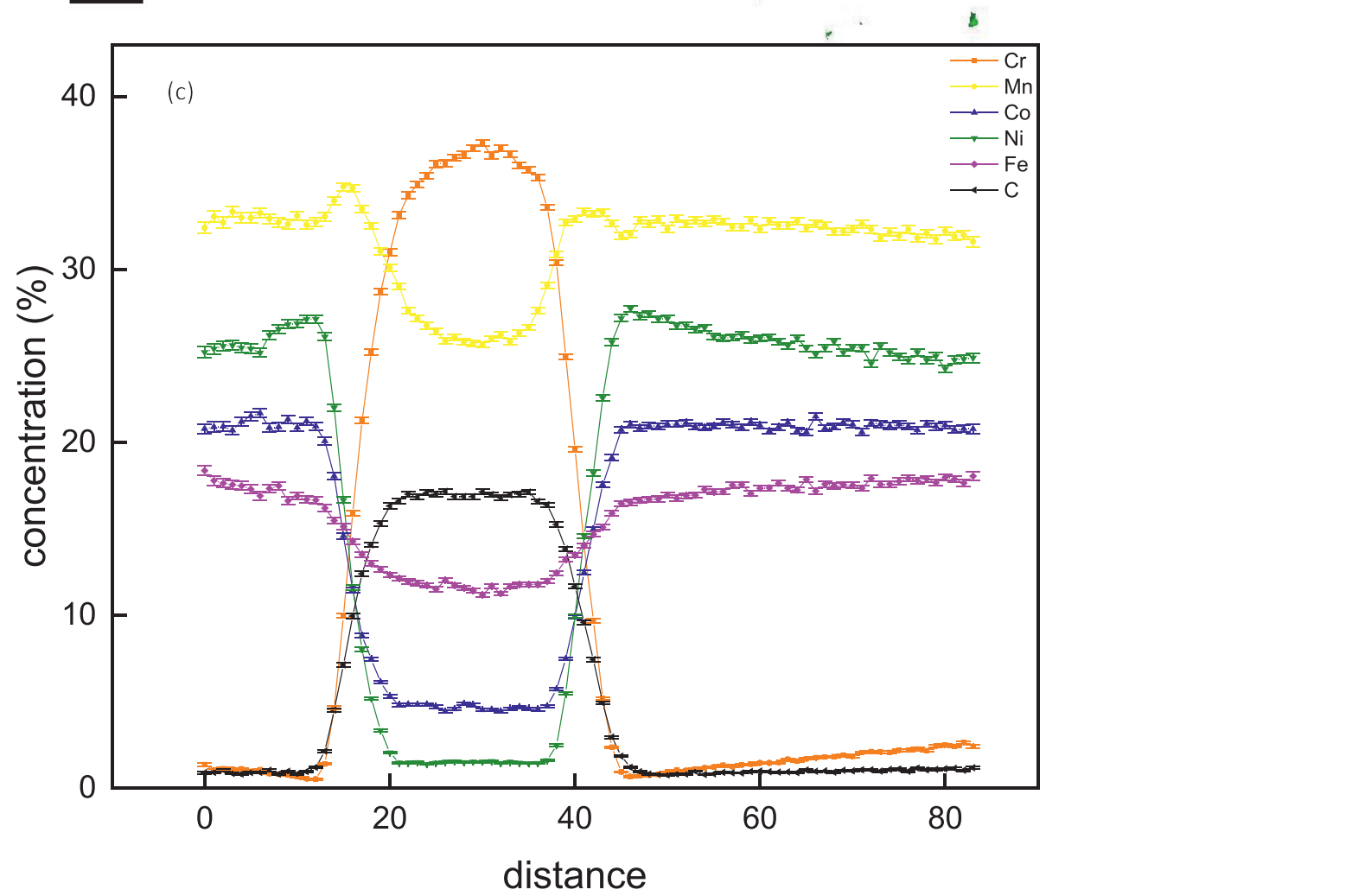

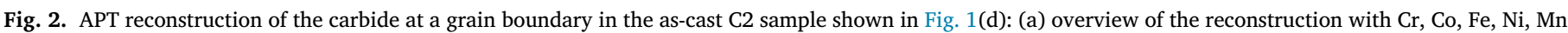

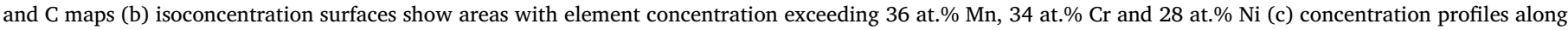
the red arrow shown in (b).

high-angle annular dark-field (HAADF) images (see the Fig.S1 in Supplementary materials). It is worth noting that all grain boundaries were taken into account, including twin boundaries, and therefore the estimated grain size includes the twins as well. However, we should keep in mind that the calculated grain size is the minimum dimension of the crystal, which has an ellipsoid shape after HPT processing [52].

Fig. 5 shows the XRD patterns of HEAs with different $C$ contents after three turns of HPT. The measurements were done at the periphery of the HPT discs; the obtained subgrain size, dislocation density, and lattice parameter are summarized in Table 2 . Only fcc phase peaks are present in the pattern suggesting that the fcc phase is stable during the HPT processing. This observation is consistent with the TEM SAED patterns (inserts in Fig. 4). It is apparent that the peaks of the C2N3 alloy are broader than these of C0N3 and C0.5N3 alloys, due to the smaller grain
Table 2

The grain/crystallite sizes determined by STEM/CMWP method, the dislocation density $\rho$, the lattice parameter a.

\begin{tabular}{lllll}
\hline Alloys & area $(\mathrm{nm})$ & d by STEM $(\mathrm{nm})$ & $\rho\left(10^{16} \mathrm{~m}^{-2}\right)$ & a $(\AA)$ \\
\hline C0N3 & 22.4 & 45 & 0.57 & $3.5949( \pm 0.00048)$ \\
C0.5N3 & 17.7 & 29 & 1.85 & $3.5955( \pm 0.00034)$ \\
C2N3 & 16.5 & 17 & 8.26 & $3.6054( \pm 0.00064)$ \\
\hline
\end{tabular}

sizes and high dislocation density, as shown in Table 2. Meanwhile, the maximums of the C2N3 alloy shift towards lower diffraction angles as is evident from an enlarged $2 \theta$ angle peaks image showed in the righthand side of Fig. 5. This shifting suggests that $C$ dissolves mostly in the fcc matrix and induces an increase of the lattice parameter shown in 

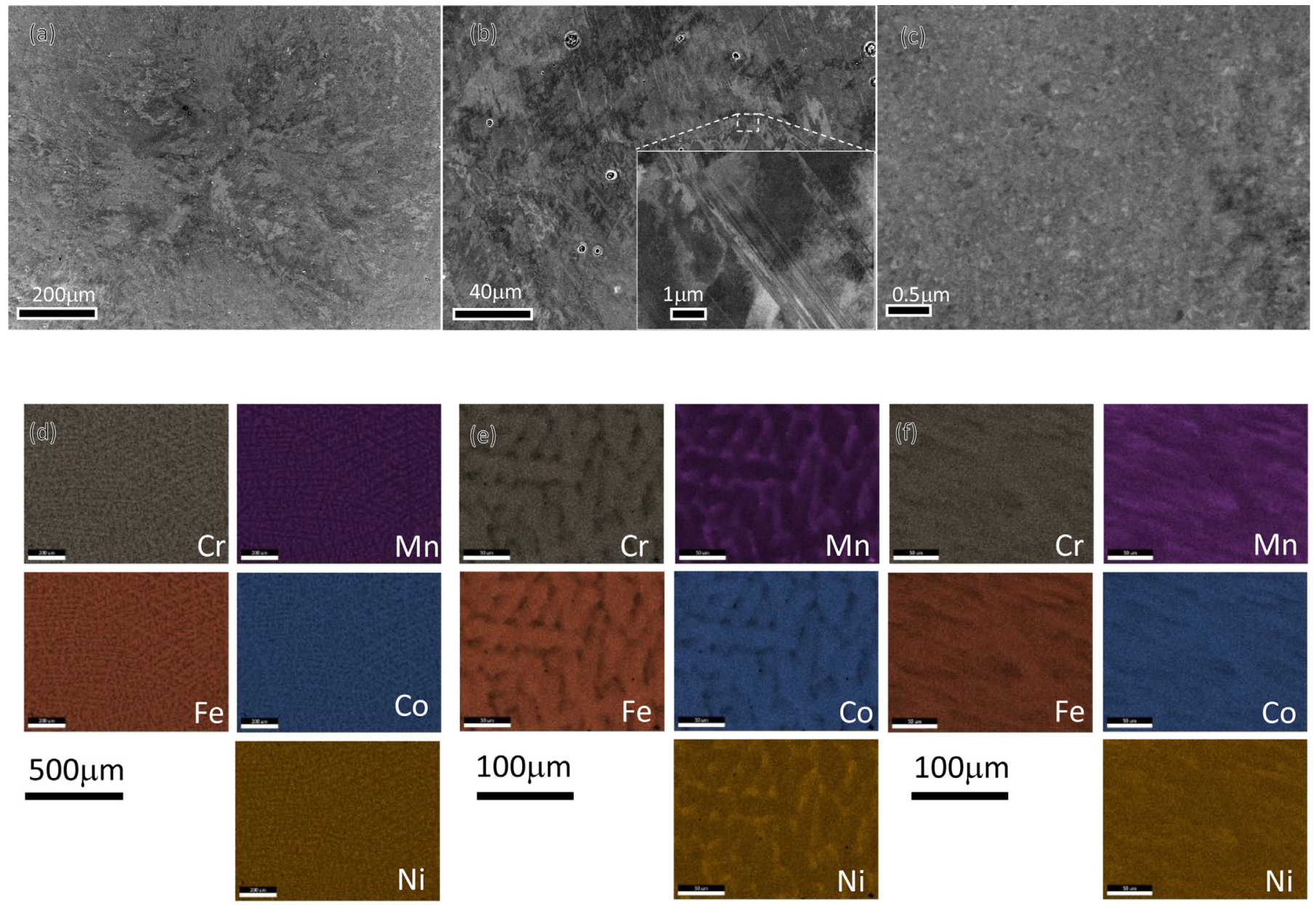

Fig. 3. Microstructure evolution of the $\mathrm{C} 0$ alloy during HPT: (a) center position without shear strain; (b) deformation structure with twinning, the equivalent strain $\sim 0.6$; (c) the microstructure at the edge of HPT disk, the equivalent strain $\sim 4$; (d-f) the EDS elemental maps corresponding to areas shown in (a-c).

Table 2. The lattice parameter of C0N3 and C0.5N3 are almost the same implying that the distortion caused by $\mathrm{C}$ atoms in the $\mathrm{C} 0.5 \mathrm{~N} 3$ alloy is quite small. Note that the diffraction peaks of carbides are not detected, probably due to a small volume fraction and nano-size of the carbides after HPT.

Fig. 6 presents the chemical composition of C2N3 alloy obtained using the 3-D APT reconstruction. The reconstruction volume contains a number of grains according to the measurements on TEM images in Fig. 4(a-c). The elemental distributions illustrate a single phase solid solution character of the material with chemical homogenity at the nanoscale. No obvious segrerations or $\mathrm{C}$, Cr-rich precipitates are observed. The carbides are likewise not detected by the APT tecnhique due to two conceivable reasons: (i) the initial brittle carbides fractured into finer pieces during HPT processing and dissolve in the alloy matrix under the high strain [53]; (ii) the fine shattered carbides are not detected due to the limited volume measured.

Since no carbides are detected in the HPT-processed alloy using the methods of XRD pattern (Fig. 5), TEM images and SAED patterns (Fig. 4), and APT analysis (Fig. 6), we can conclude that the carbides are most likely dissolved in the alloy matrix during HPT. In order to investigate the $\mathrm{C}$ atom distribution in the $\mathrm{C} 2 \mathrm{~N} 3$ alloy more precisely, a cuboid with the thickness of $20 \mathrm{~nm}$ showing only $\mathrm{C}$ atoms with the concentration larger than 4 at.\% was cut out from the 3D reconstruction in Fig. 6 as displayed in Fig. 7(a). The fluctuations of the $C$ concentration with a length scale from 5 to $30 \mathrm{~nm}$ that corresponds to the grain size scale in the C2N3 alloy (Table 2) are clearly seen. Meanwhile, a C concentration profile was plotted to clarify the segregation (Fig. 7(b)) inside the $\varnothing 5 \times 50 \mathrm{~nm}^{3}$ cylinder shown in (Fig. 7(a)). The C content reaches $\sim 5-7$ at.\%, which is much higher than the nominal concentration of $\mathrm{C}$ in the alloy. Meanwhile the concentration profiles of $\mathrm{Cr}$, Mn and Fe do not show significant fluctuations in Fig. 7(c). Hence, we propose that the $\mathrm{C}$ atoms segregated at GBs during the HPT processing in the C2N3 alloy.

\subsection{Mechanical properties}

\subsubsection{Hardness}

Fig. 8 shows the hardness variation along the radius of the HPT processed HEA samples with the different $C$ content after $0.5,1$ and 3 rotations. The corresponding von Mises equivalent strain is also indicated. The hardness of the C2 sample after HPT processing through different numbers of turns is shown in Fig. 8a in comparison with the initial hardness of the as-cast state (dashed line). A large gradient of the hardness occurs along the disk radius in all samples. After 0.5 turn, the hardness gradually increases from $\sim 340 \mathrm{HV}$ in the center to $\sim 620 \mathrm{HV}$ at the periphery. With increasing number of rotations, the hardness in the center becomes higher, and its increase along the radius becomes steeper until it reaches the saturation at $\sim 620 \mathrm{HV}$. In the sample after three rotations, the hardness saturation is observed at the distance of $1.5 \mathrm{~mm}$ from the center. The hardness saturation most likely indicates achieving a stable (minimum upon these conditions) grain size. Similar behavior was observed in the CO and C0.5 samples.

It is apparent that an increase in the $C$ content leads to a higher hardness of the studied HEAs Fig. 8(b), however the overall appearance 

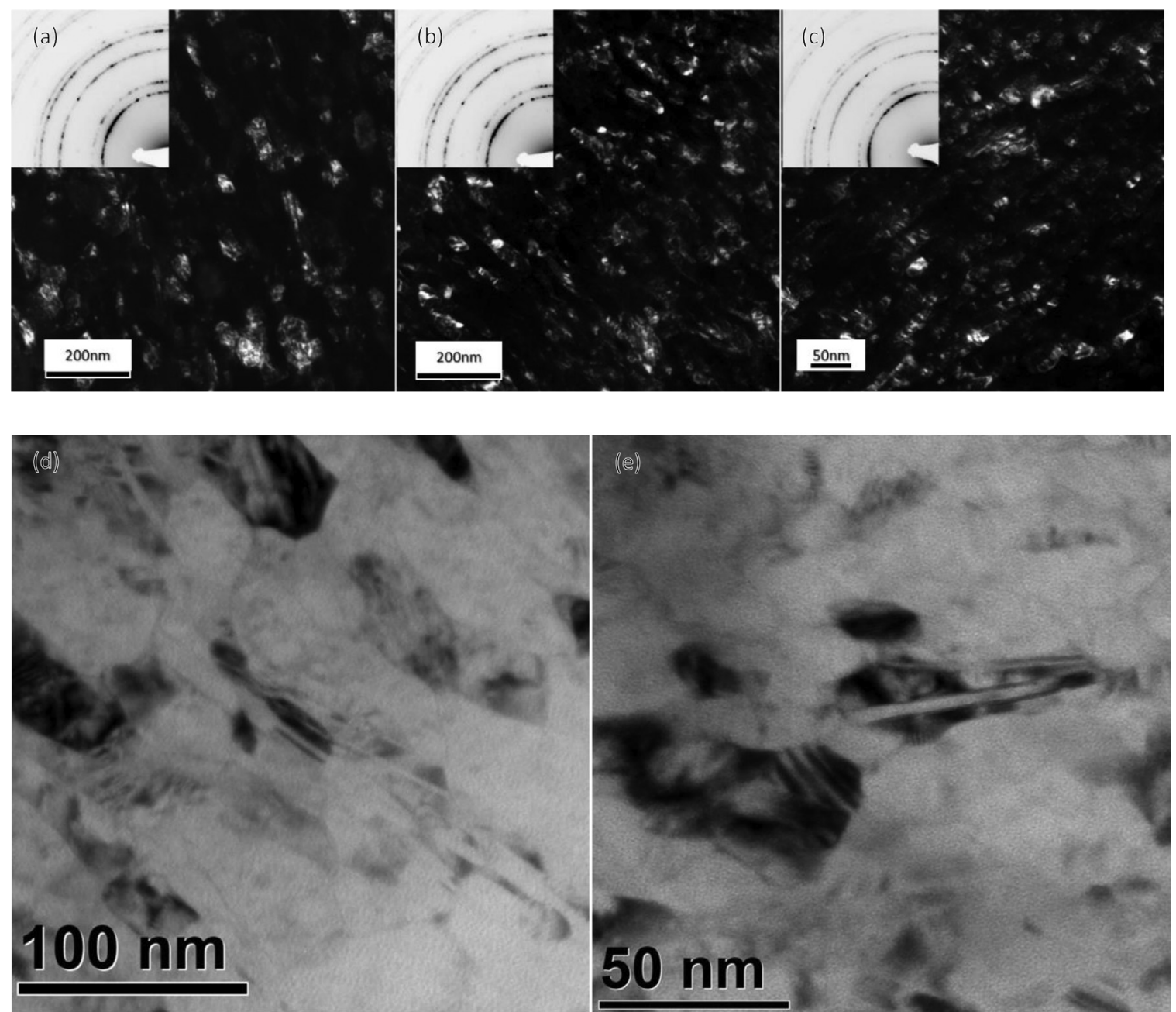

Fig. 4. TEM dark-field images and corresponding SAED patterns (inserts) of HEAs processed by HPT with 3 turns: (a) C0N3; (b) C0.5N3; (c) C2-N3; (d, e) higher magnification bright field images for C0.5N3 and C2N3 alloys, respectively.

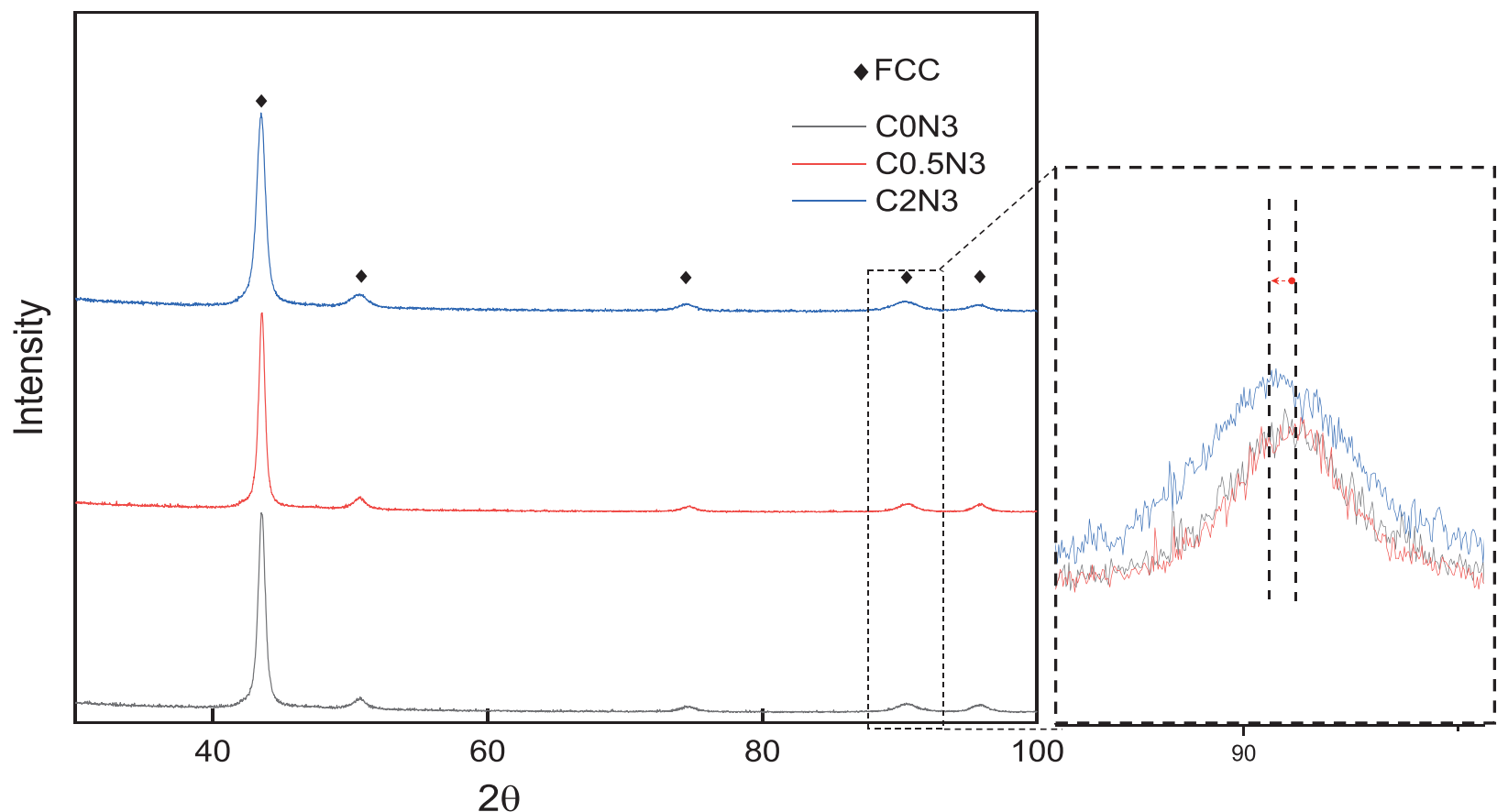

Fig. 5. XRD diffraction patterns for the high entropy alloys with different $\mathrm{C}$ contents after three turns of HPT. The insert shows elarged (311) peaks. 
$\mathrm{Cr}$

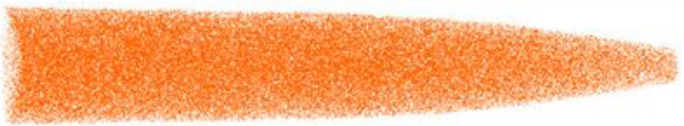

Co

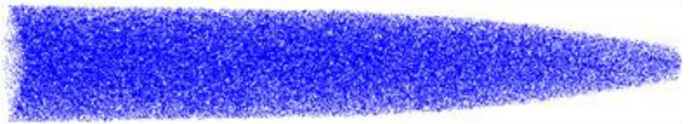

$\mathrm{Fe}$

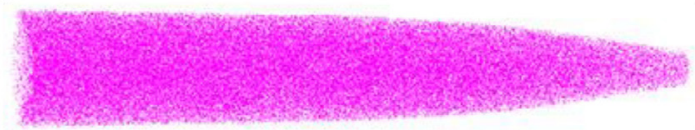

C

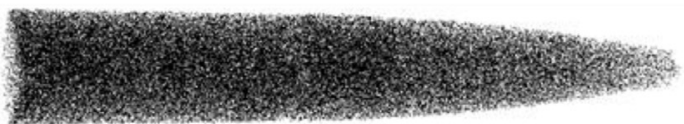

$\mathrm{Ni}$

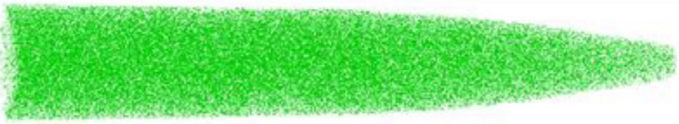

$\mathrm{Mn}$

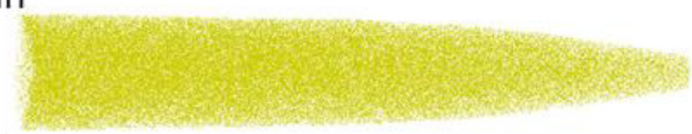

\section{$100 \mathrm{~nm}$}

Fig. 6. APT reconstruction the C2N3 alloy at saturation: an overview of the reconstruction with $\mathrm{Cr}, \mathrm{Co}, \mathrm{Fe}, \mathrm{Ni}, \mathrm{Mn}$ and $\mathrm{C}$ maps.
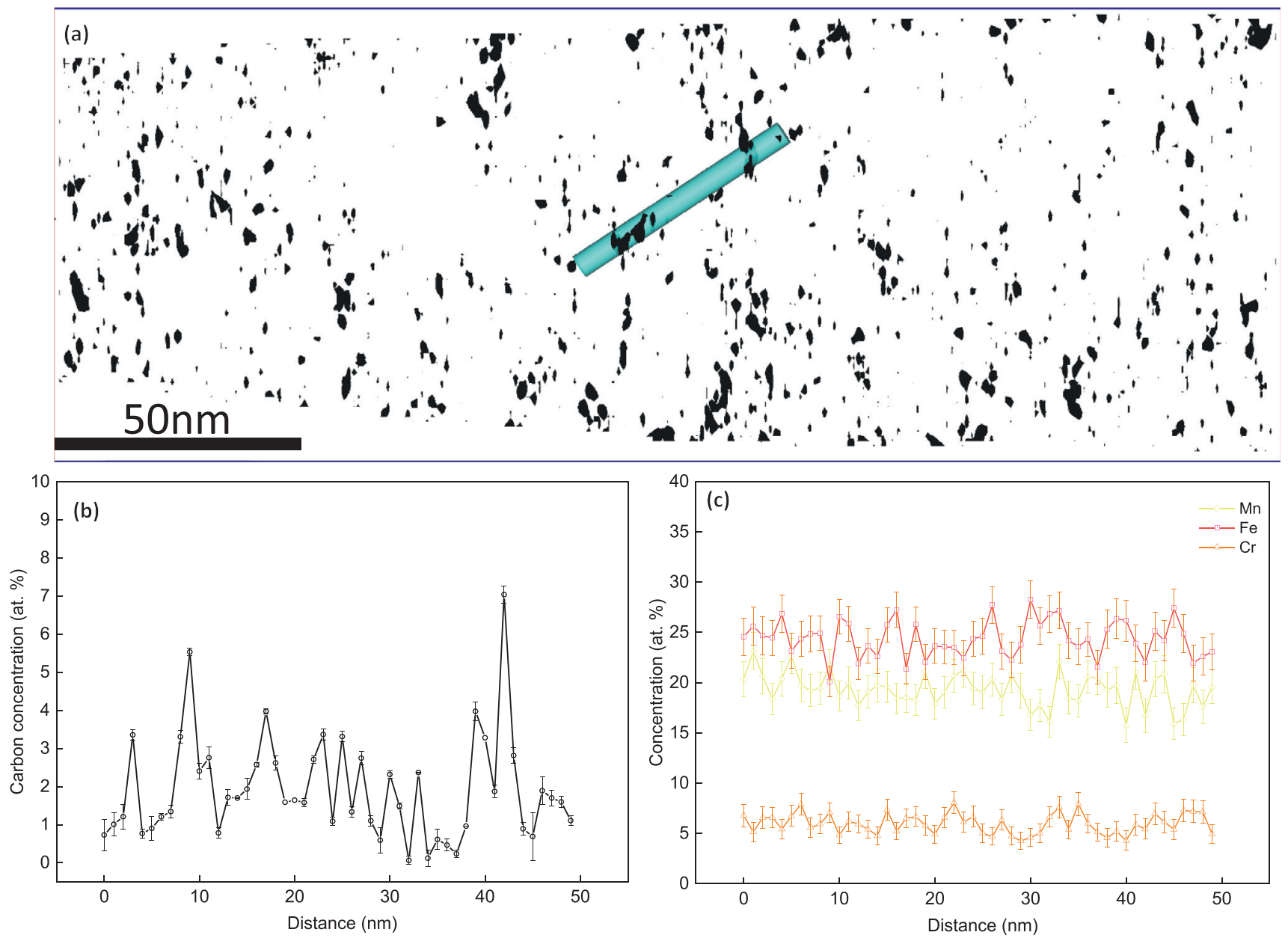

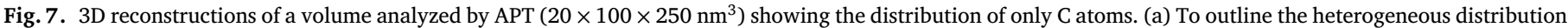

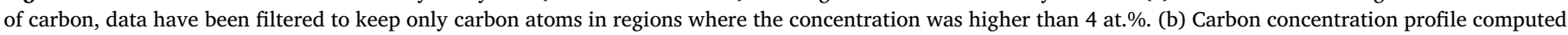
from the left to the right across the cylinder shown in (a); (c) $\mathrm{Cr}$, Mn and Fe concentration profiles across the cylinder shown in (a).

of the hardness distribution along the HPT-sample diameter with a drop in the center and the hardness saturation towards the periphery of the disk is very similar for all three alloy compositions. Fig. 8(c) shows the variations of the hardness values with Von Mises equivalent strain for the $\mathrm{C} 0$ and $\mathrm{C} 2$ samples. It confirms that the saturation occurs at the equivalent strain higher than 20 in both alloys.

\subsubsection{Tensile tests}

Fig. 9 shows representative tensile stress-strain curves for the as-cast and HPT-processed alloys with different $\mathrm{C}$ contents at room temperature. The coarse-grained alloys exhibit a considerable uniform elongation and high ultimate strength as a result of planar slip, high frictional stress and dynamic Hall-Petch effect (Fig. 9(a)), similarly to other 

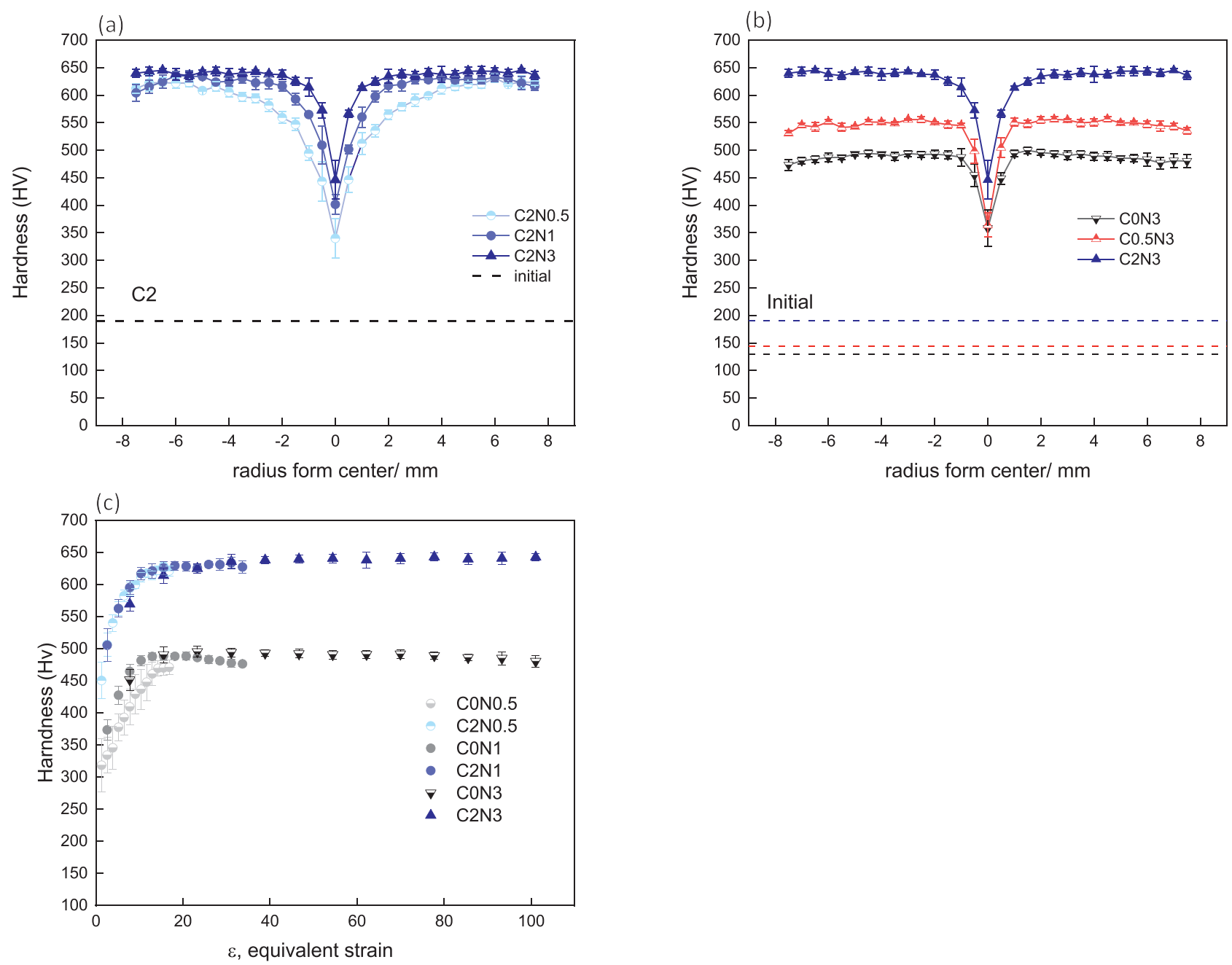

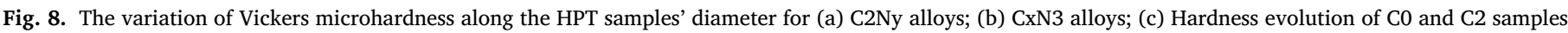

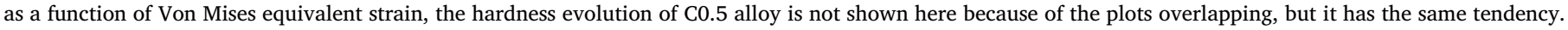
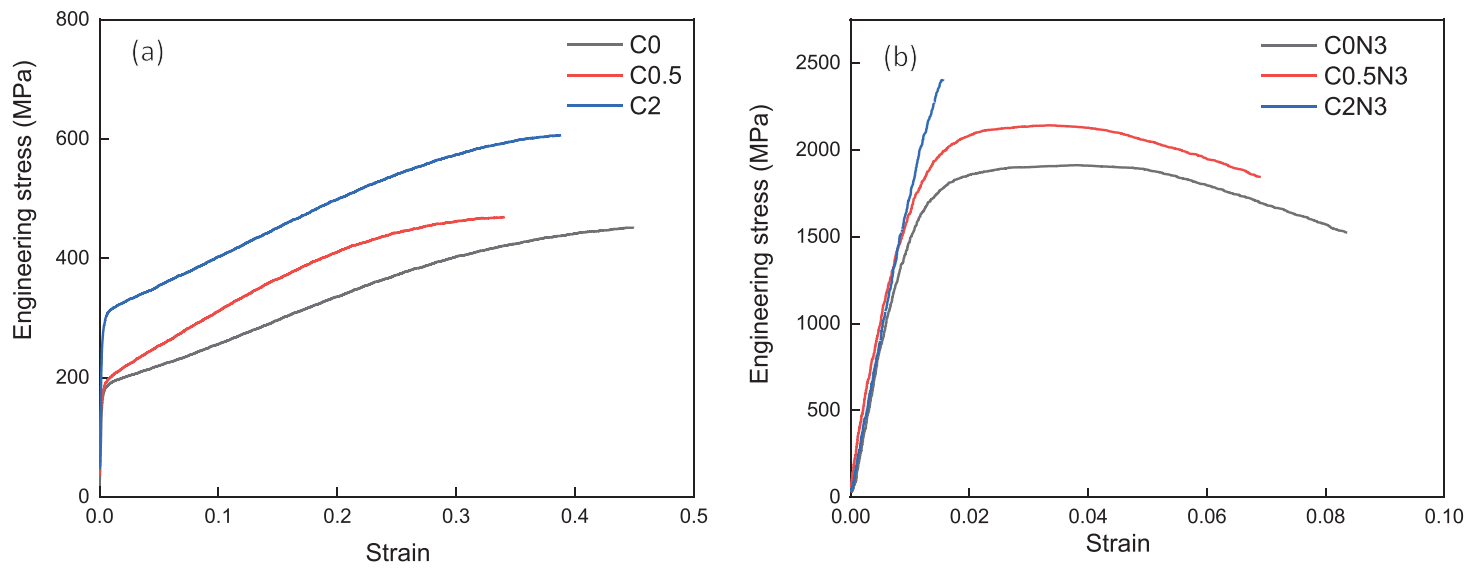

Fig. 9. The tensile stress-strain curves of the studied alloys: (a) as-cast state; (b) CxN3 alloys.

fcc HEAs [2,18,54]. Fig. 9(b) shows stress-strain curves of the samples with different $C$ content processed by three HPT turns. The HPTprocessed samples show remarkably high strength at the expense of ductility (typical for cold-worked alloys) comparing with the as-cast states. The CON3 alloy still shows a reasonable ductility with the elongation to failure of $\sim 8 \%$. The C0.5N3 state demonstrates similar behavior. On the other hand, the C2N3 samples shows almost brittle fracture with negligibly small ductility and ultra-high fracture strength of $\sim 2.4 \mathrm{GPa}$. The tensile mechanical properties of the alloys are summarized in Table 3.

The fracture surfaces of the alloys after HPT and tensile testing are shown in Fig. 10. Deep large dimples form usually on the surface of the Cantor type alloys in the as-cast or coarse-grained conditions thereby indicating a ductile fracture behavior $[18,55]$. Meanwhile, the HPT pro- 
Table 3

Mechanical properties of the studied alloys: yield strength (YS), ultimate tensile strength (UTS), uniform strain $\left(\varepsilon_{\mathrm{u}}\right)$, strain at fracture $\left(\varepsilon_{\mathrm{f}}\right)$ and Vickers hardness.

\begin{tabular}{lllllll}
\hline C content at. $\%$ & State & YS, MPa & UTS, MPa & $\varepsilon_{\mathrm{u}}, \%$ & $\varepsilon_{\mathrm{f}}, \%$ & Hardness, HV \\
\hline 0 & As-cast & 181 & 451 & 43.3 & 44.4 & 129 \\
& N3 & 1667 & 1912 & 2.6 & 7.4 & 490 \\
0.5 & As-cast & 190 & 468 & 33.2 & 35.4 & 144 \\
& N3 & 1898 & 2141 & 2.1 & 5.7 & 550 \\
& As-cast & 291 & 605 & 37.8 & 39.5 & 190 \\
& N3 & $2402^{*}$ & - & - & 0.16 & 640 \\
\hline
\end{tabular}

* Fracture occurred before the yield point.

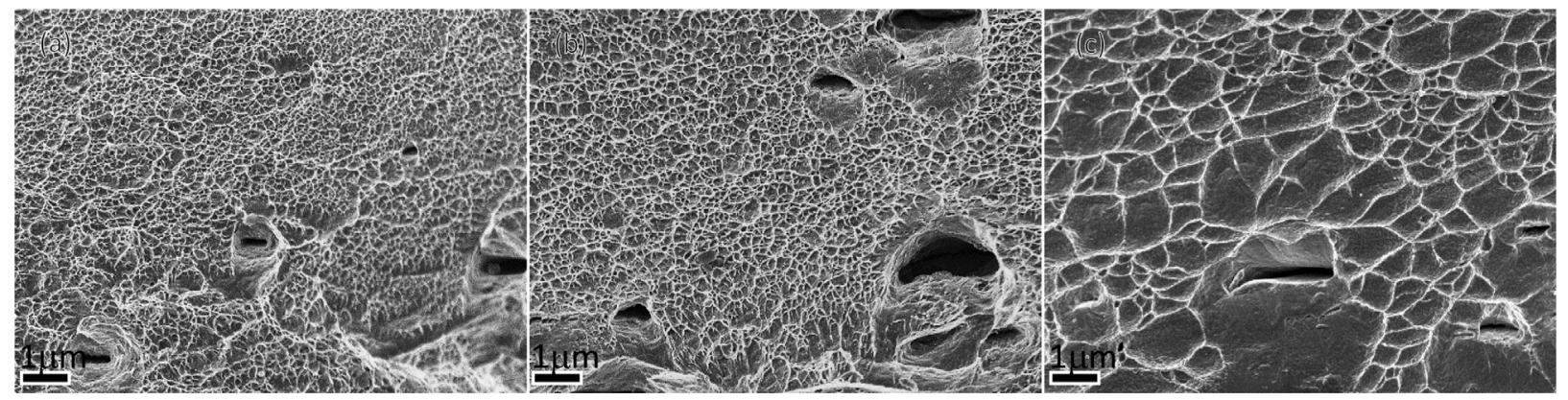

Fig. 10. Fracture morphology of tensile samples of $\mathrm{CON} 3$ (a), $\mathrm{C} 0.5 \mathrm{~N} 3$ (b) and C2N3 (c) alloys.

cessed alloys also do not indicate obvious brittle fracture characteristics. Fine dimples are densely distributed on the fracture surfaces of the CON3 and C0.5N3 alloys (Fig. 10a, b), which is corresponding to low ductility shown in Fig. 9(b) and Table 3. The dimples size of these two alloys is almost the same, ranging from tens to hundreds of nanometers that is considerably larger than the grain size. However, in the C2N3 alloy the "dimples" are much larger than in the other two alloys. The characteristics of the fracture surface in the C2N3 alloy can be characterized "vein pattern" which is typical of bulk metallic glasses [56,57]. The mechanisms responsible for the two types fracture morphology are different, as will be discussed below.

Additionally, some deformed "micro-cracks" surrounded by fine dimples are found on all the fracture surfaces. The C0N3 and C0.5N3 alloys show wider cracks in comparison with the $\mathrm{C} 2 \mathrm{~N} 3$ alloy due to their better ductility. Investigations of cross-sections of as-deformed specimens revealed that these cracks look like thin and elongated ellipsoid shaped voids were formed already during the HPT processing around oxides and sulfides inclusions, fractured into fine particles (see Fig. S2 in Supplementary).

\section{Discussion}

The present study has revealed a significant effect of $\mathrm{C}$ alloying on the grain refinement and mechanical response of the CoCrFeMnNi alloys. Several aspects of the alloys' behavior will be analyzed in detail below.

\subsection{Mechanisms of grain refinement and carbide dissolution}

Plastic deformation of HEAs has been investigated for over 10 years since they were first discovered $[1,58]$. However, studies on structure and properties of single phase fcc HEAs processed via HPT deformation have been reported only in the last few years [29,59]. In this study, the microstructural observations indicate that $\mathrm{C}$ alloying of the CoCrFeMnNi high entropy alloy significantly contributes to grain refinement during HPT processing.

It is known that the microstructure evolution during HPT occurs in a series of stages. The schematic describing the grain refinement of $\mathrm{CO}$ alloy during the HPT is shown in Fig. 11(a). It starts with the formation of a cell structure and deformation twins with high dislocation density located in the cell boundaries [22,60]. Subsequently, inhomogeneous microstructure with a broad grain size and boundary misorientation distributions forms, which maintains over a wide range of shear strains. Nevertheless, the mean grain size gradually decreases with strain increasing and the permanent storage of dislocations in cell boundaries leads to an increase of their misorientations. Ultimately, a steady stage is reached where the mean grain size achieves the lowest value, and neither the mean grain size nor the GB misorientation distribution can be influenced by further deformation [22].

The main feature of the microstructure evolution of low stacking fault energy (SFE) fcc alloys during plastic deformation is intensive deformation twinning, which significantly facilitates the grain refinement during SPD [61]. In the materials that deform by both twinning and slip the kinetics of microstructure refinement can be enhanced due to intensive twins formation [62,63]. Thin deformation twins, which are separated from the matrix by high-angle boundaries, readily transform into a chain of grains during the deformation.

Deformation twinning in the Cantor alloy is associated with its low $\mathrm{SFE}$ of $\sim 21 \mathrm{~mJ} / \mathrm{m}^{2}$ at room temperature $[64,65]$. The mean grain size of saturated microstructure is $\sim 45 \mathrm{~nm}$ (Fig. $4 \mathrm{a}$ ), which is similar to the behavior of the equiatomic CoCrFeMnNi alloy during HPT [29]. It suggests that the two alloys have comparable SFE in essential. It was found recently based on first principles calculations that addition of $\mathrm{C}$ in $\mathrm{CoCr}$ FeMnNi increases SFE [66]. This finding was confirmed in medium entropy CrCoNi alloy [32].

With the $\mathrm{C}$ content increasing, the mean grain size of the saturated microstructure shows a decreasing trend. The mean grain sizes are 29 and $17 \mathrm{~nm}$ for the C0.5N3 and C2N3 alloys, respectively. The reduction in grain size can be associated with the segregation of $\mathrm{C}$ on GBs (Fig. 7) as a result of the dissolution of carbides during HPT. Similar results were also reported in C45 steel [53,67] and pearlitic steel [68]. Several mechanisms may lead to strain induced dissolution of precipitates during SPD. It is known that high dislocation density [22], nonequilibrium GBs [69] and high vacancy concentrations [70] which form during SPD, provide the diffusion paths for interstitial $\mathrm{C}$ atoms. All the defects contribute to the diffusion or the atomic mobility during SPD: the dislocations can drag solutes [71] and act as diffusion pipes [72], the GBs are the fast diffusion paths and also drag solute when they move 


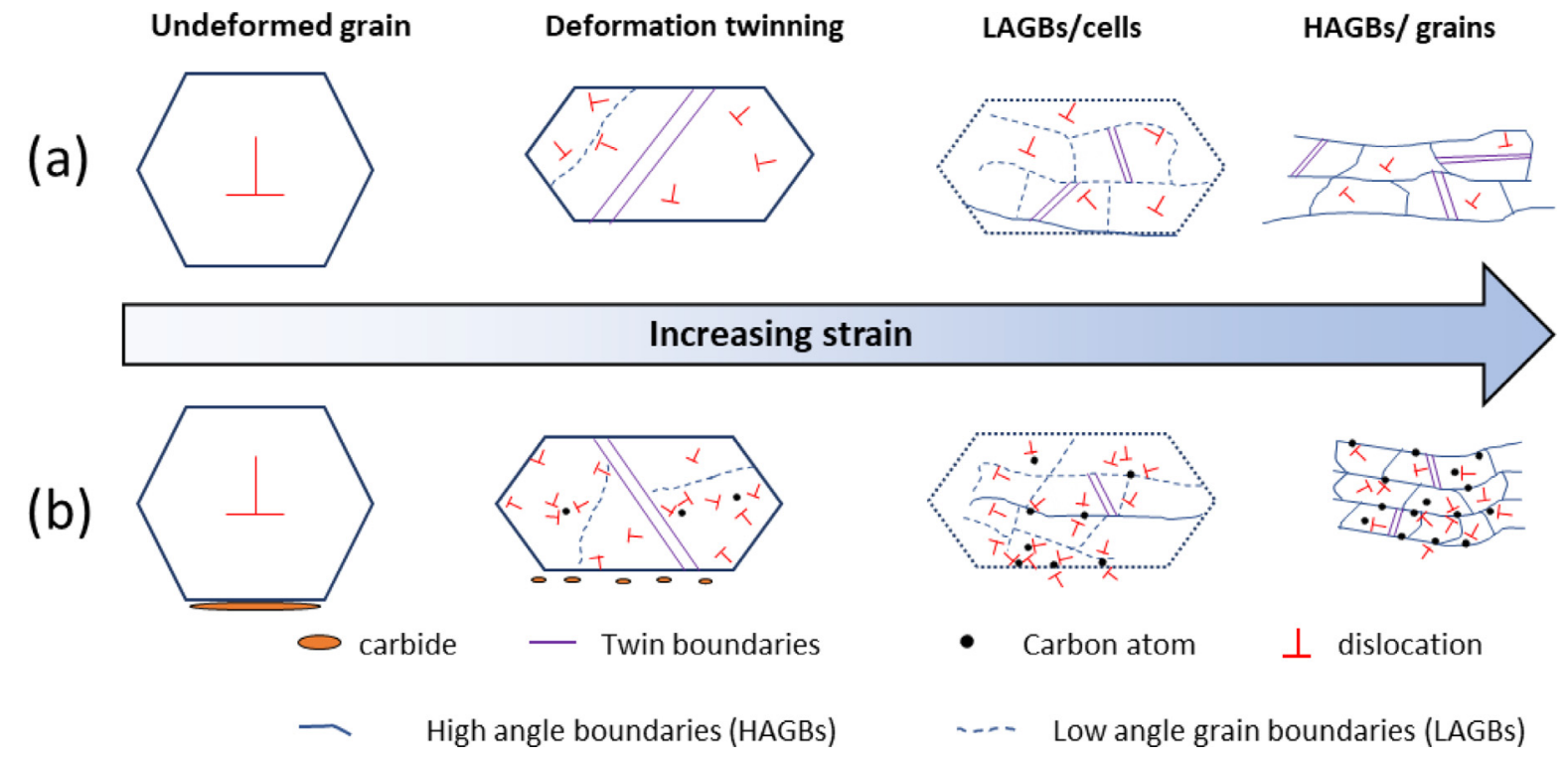

Fig. 11. Schematic of microstructure evolution during HPT of: (a) C0 alloy; (b) C2 alloy.

during SPD [73-75], and the strain induced vacancies directly enhance the atomic diffusion, respectively.

It is known that interstitial $\mathrm{C}$ atoms have a strong effect on dislocation cross-slip. Grain refinement starts from grain subdivision during plastic deformation on several length scales which is found to be universal in wavy glide materials like e.g., Ni [76] and iron [77]. However, grain subdivision also occurs in planar glide materials such as low SFE alloys, e.g., HEA [31] and TWIP steel [78]. In our case, different C contents from 0 to 2 at.\% (nominal) was added to CoCrFeMnNi alloy. Despite some segregation formed on the GBs in C2 alloy, the C concentration in the matrix is close to the nominal one ( $\approx 2$ at.\%). The schematic describing the grain refinement of C2 alloy during the HPT is shown in Fig. 11(b). Due to the strong effect of $\mathrm{C}$ atoms, it results in a gradual transition in the type of dislocation configuration from planar (Taylor lattice) to wavy (cells and cell blocks) [78], which contributes to the formation of cell blocks. Since the size of initial cell blocks is limited by $\mathrm{C}$ atoms pinning the dislocations, the fragmentation trends to reduce the sub-grain size resulting in finer grains. GB migration is necessary to obtain a steady-state microstructure and to avoid a continuous decrease the grain size [79]. However, the $\mathrm{C}$ segregation at GBs occurring during HPT provides the effect of pinning of the boundary migration; grains cannot grow up which results in finer grain size in the $\mathrm{C} 2$ and $\mathrm{C} 0.5$ alloys comparing with the $\mathrm{C} 0$ alloy. In pure $\mathrm{Ni}$, the influence of $\mathrm{C}$ in the saturated microstructure was also analyzed [80]. It was revealed that the higher $\mathrm{C}$ content led to finer grain size after HPT in the saturation regime.

The evaluation of the XRD peak profiles revealed notably high values of dislocation density in all HPT-processed alloys (Table 2). It is known that the dislocation density in SPD processed alloys is low because dislocations usually sink into GBs or self-organize into ordered substructures like sub-boundaries [22]. From dislocation densities in Table 2 we can approximately estimate, how many dislocations reside in one grain. In the CON3 alloy, each grain contains fewer than 30 dislocations. Comparing with the C2N3 alloy which has much smaller grain size, but contains about 50 dislocations per grain. These results provide support to the argument that $\mathrm{C}$ interstitial enhances the storage of dislocations during HPT processing even in grains with the finest size.

\subsection{Strengthening mechanisms in nanostructured HEAs}

The mechanical properties at both room and liquid nitrogen temperature of as-cast high entropy alloys under investigation with different
C content have been discussed earlier in [18]. A significant increase of strength with increasing $\mathrm{C}$ content has been demonstrated. C doping contributes to the solid solution strengthening due to increased lattice friction stress. When comparing our results on mechanical behavior of as-cast $\mathrm{CoCrFeMnNiC}_{\mathrm{x}}$ alloys [18], one should keep in mind that in our case the tensile tests have been performed using miniature specimens with a gauge length of $3 \mathrm{~mm}$ and the cross-section area of $0.6 \mathrm{~mm}^{2}$ which means that just several grains present in the sample cross section. It is known that the dimensions of tensile specimens can influence the resulting mechanical properties especially in respect of uniform elongation.

In this study, we focus mainly on the alloys processed by HPT for three turns. High pressure torsion resulted in a dramatic decrease of the alloys grain size down to nanometer-range. Mean grain size of the microstructure formed after three HPT turns was 47, 29 and $17 \mathrm{~nm}$, in samples with the C content of $0,0.5$ and 2 at.\%, respectively. There is a general agreement that for materials with such a small grain sizes dislocation slip becomes less important and even ceases to operate. Indeed, if we calculate the contributions of all hardening mechanisms based on dislocation slip (Hall-Petch grain boundary strengthening, strengthening due to stored dislocations and solid solution strengthening) we obtain unrealistically high strength values.

Grain refinement is one of the reason for governing strength of polycrystalline materials, where the strengthening can be described in terms of the empirical Hall-Petch relation [81,82]:

$\sigma_{g b}=k_{y} D^{-1 / 2}$

where $\mathrm{D}$ is the mean grain size and $\mathrm{k}_{\mathrm{y}}$ is the Hall-Petch slope. We used a coefficient $\mathrm{k}_{\mathrm{y}}=0.494 \mathrm{MPa} \cdot \mathrm{m}^{1 / 2}$ obtained for a coarse-grained Cantor alloy [2]. The respective Hall-Petch contributions for the three alloys are summarized in Fig. 11.

The contribution of stored dislocations to the yield strength can be obtained from the Taylor equation [83]:

$\sigma_{\text {Taylor }}=\mathrm{M}_{\mathrm{T}} \alpha \mu b \sqrt{\rho}$

where $\mathrm{M}_{T}$ is 3.06, the Taylor factor meaning orientation factor for fcc polycrystalline matrix, $\alpha$ is a constant equal to 0.2 for fcc alloys, $\mu$ is the shear modulus, here we use the modulus of Cantor alloy for this calculation [84], $b$ is the magnitude of Burgers vector and $\rho$ is the dis- 
location density [85]. Again, the calculated contributions are presented in Fig. 11.

$\mathrm{C}$ atoms in solid solution contribute to the frictional stress of the alloy, and solid solution strengthening can be calculated as proposed in Refs. [86,87]:

$\Delta \sigma_{s s}=f G\left(c \alpha^{2} \delta^{2}\right)^{2 / 3}$

$\delta=\frac{a_{0}-a_{i n t}}{(1-c) a_{0}}$

Where the $f$ is dimensionless parameter, $c$ is the concentration of C, $\delta$ describes the lattice mismatch, and $\alpha$ is a dimensionless parameter that describes the type of dislocations, which is $3 \sim 16$ for screw dislocations, and $>16$ for edge dislocations, here we use $\alpha=16 . a_{0}$ is the lattice constant of the $\mathrm{C} 0$ alloy, and $a_{\text {int }}$ is the lattice constant of the C containing alloys. The $\mathrm{C}$ solid solution strengthening is $\sim 1 \mathrm{MPa}$ and $\sim 85 \mathrm{MPa}$ for C0.5N3 and C2N3 alloys, respectively, which is comparable with the experimental values of $9 \mathrm{MPa}$ and $110 \mathrm{MPa}$ obtained from the measured yield strength of the as-cast alloys (Table 3 ).

Furthermore, $\mathrm{C}$ segregation at GBs of nano-grains revealed in C2N3 alloy (Fig. 7) likely also contributes to the increased yield strength. Meanwhile, published studies show that GB segregation, formed during SPD in some alloys, provide an additional strengthening mechanism. For example, in related work, Mo atoms segregating on GBs in nano-structured Ni-Mo alloy contributed to ultrahigh hardness and increased GB stability [88]; Mo, Si and Cr segregated on GBs in UFG 316 steel were produced by HPT at $400{ }^{\circ} \mathrm{C}$ while the segregation was not detected at room temperature and the segregation provided the comparable strength to that of RT processed alloy [89]; Xu et al. reported that ultrahigh strength with stable nanostructures was achieved in $\mathrm{Al}$ alloys with deformation-induced GB segregation of $\mathrm{Cu}$ [90]. Bobylev et al. proposed a model to explain the enhanced strength of UFG Al alloys provided by $\mathrm{Mg}$ segregation. In this model, segregated $\mathrm{Mg}$ atoms were treated as homogeneous ellipsoidal inclusions acting as the sources of elastic stresses affecting the emission of lattice dislocations from GBs [91]. It is plausible that in the present study, the interstitial C atoms segregating on GBs in the C2N3 alloy provided extra strength comparing with that of the $\mathrm{CO}$ alloy after HPT processing, however it is difficult to estimate this effect as the physical mechanisms behind it are still not clear.

Finally, the calculated grain boundaries strengthening, dislocation strengthening contributions in comparison with experimentally measured yield strengths are shown in Fig. 12. The solid solution strengthening is not shown due to its small value. It is clearly seen that GB strengthening alone is already higher than the experimentally measured yield strength in all three HPT-processed alloys. These results indicate that the values of grain boundary strengthening obtained using the HallPetch equation are overestimated, and a deviation from the Hall-Petch law is observed in nanocrystalline C-doped CoCrFeMnNi alloys. Such deviations are well documented in literature for many pure nanocrystalline metals because Hall-Petch coefficient of bulk nano-crystalline alloys is anticipated to be smaller than that in coarse grained alloys and finally the inverse Hall-Petch was observed with the grain size deceasing to a few nanometers grain size [92-95]. For instance, in pure copper at the grain size below $10 \mathrm{~nm}$, the flow stress decreases sharply with decreasing grain size while increases for grain sizes larger than $15 \mathrm{~nm}$, which indicates nanocrystalline copper has a strongest grain size effect at of 10-15 nm [93]. Furthermore, the inverse Hall-Petch relationship for a nanocrystalline FeNiCrCoCu HEA was predicted recently using molecular dynamics simulations [96]. In our case, the yield strength of the studied alloys after three rotations keeps increasing with increasing C content while the grain size decreases from 45 to $17 \mathrm{~nm}$.

The dislocation strengthening contribution is around $0.8 \mathrm{GPa}$ in the CON3 alloy, approximately half of the measured yield strength, which is common in SPD processed HEAs [24]. The dislocation strengthening of the C0.5N3 and C2N3 alloys achieved 1.6 GPa and 3.3 GPa, respec- tively (Fig. 12). Especially, the calculated dislocation strengthening in the C2N3 alloy is even higher than its experimental yield strength which points towards the operation of totally different strengthening mechanisms than the conventional Taylor and Hall-Petch ones.

In the interstitial HEAs with the fine, micron-scaled grains, GBs provide the major contribution to the strength as they serve as effective obstacles for dislocation slip [17,97]. The estimations made in this work demonstrate that in nanostructured HEAs dislocation slip and grain boundary strengthening become less important. The smaller is the grain size, the larger is the discrepancy between the calculated and experimental yield strength values, that means the less dislocation slip contributed to plasticity. However, we still observe the higher YS for smaller grain size and not the opposite as it is expected from the inverse Hall-Petch relationship.

Obviously, $\mathrm{C}$ plays an important role in hardening in both the as-cast and HPT-processed alloys (Table 3 and Fig. 9). For the as-cast alloys, the mechanical properties were mostly affected by the $\mathrm{C}$ concentration in the solid solution. For nanocrystalline alloys, impact of $\mathrm{C}$ alloying on mechanical behavior is more complicated. Generally, the plastic deformation of polycrystalline alloys is dominated by dislocation pile-ups. As the grain size is decreased, the number of dislocations piled up against a grain boundary decreases since this number is a function of applied stress and of the distance to the source [92]. As it has been already mentioned, for nanocrystalline materials, an additional plasticity mechanism has been proposed to operate: grain-boundary sliding [98]. In the CON3 alloy, relatively large grain size $(45 \mathrm{~nm})$ and relatively low dislocation density $\left(0.57 \times 10^{16} \mathrm{~m}^{-2}\right)$ provided the possibility of dislocation pile-up during the plastic deformation. As a result, the CON3 alloy presents some uniform elongation of $3.8 \%$ and $8 \%$ elongation to fracture which correlates well with the fracture surface shown in Fig. 10(a). The C0.5N3 alloy exhibited a similar tendency: the pile-ups formation is restricted by the higher dislocation density $\left(1.85 \times 10^{16} \mathrm{~m}^{-2}\right)$ and smaller grain size $(29 \mathrm{~nm})$, which leaded to a lower ductility and higher strength comparing with the CON3 alloy, and probably to the emergence of grain boundary sliding. From the morphology of fracture surfaces in Fig. $10(a, b)$ these two alloys indicated the same ductile fracture condition. The formations of fine dimples may occur via the following steps: at the early stages of deformation, dislocations are emitted from GBs under the influence of applied stress, when intragranular slip is coupled with unaccommodated grain boundary sliding to facilitate voids formation at the GBs; triple junction voids and wedge cracks can also result from grain boundary sliding if resulting displacements at the boundary are not accommodated by diffusional or power law creep. These voids can grow and partially relieve the constraints on a small group of grains, individual single-crystal ligaments so created deform extensively and finally experience the failure to dimples [98].

Nevertheless, the situation in the C2N3 alloy is completely different, as this alloy exhibits different deformation and fracture behavior. Brittle fracture without any yielding or any evidences of plastic deformation was not detected in Fig. 9. A very small grain size and the ultrahigh dislocation density $\left(8.26 \times 10^{16} \mathrm{~m}^{-2}\right)$ preclude the formation of pile-ups formation and planar slip; deformation twinning is also suppressed in the fine-grained Cantor alloy [99]. Thus, the only possible way to induce plasticity is GB sliding. However, grain boundaries in this alloy are decorated with $\mathrm{C}$ segregation (Fig. 7). On the one hand, C segregation enhances GB cohesion $[100,101]$, on the other hand, they simultaneously retard grain boundary sliding which leads to high fracture strength but brittle fracture in the C2N3 sample. Focusing on the fracture surface morphology (Fig. 10(c)), the vein patterns, which are typically observed in bulk metallic glasses, appear on the fracture surface of C2N3 sample. The overall appearance of the pattern is analogous to the fracture features formed by the separation of grease between two solid plates [102]. The origin responsible for the pattern formation could be largely attributed to shear-induced structural disordering or temperature rise caused by elastic energy release in the final fracture stage [57]. High levels of tensile stresses in the crack tip lead to local dilatation 


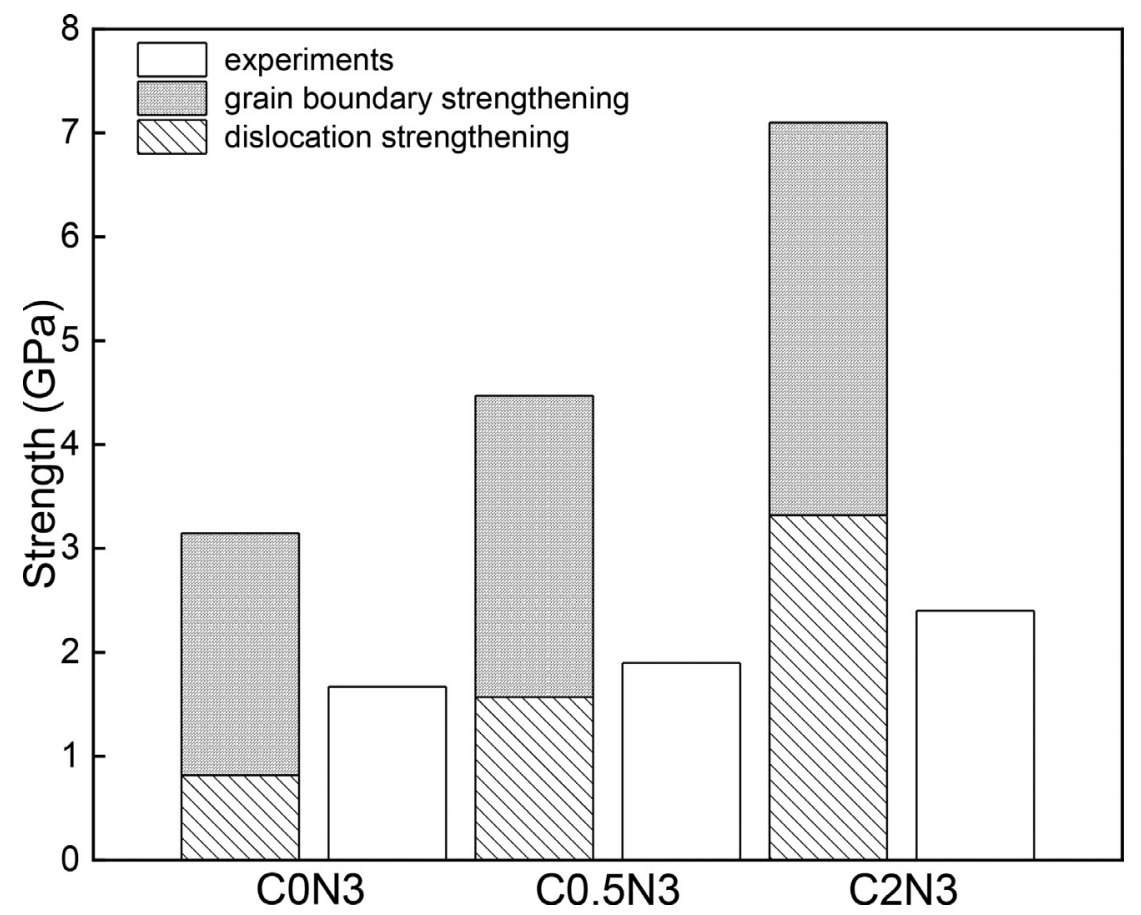

Fig. 12. The estimated contribution of GBs and dislocation strengthening to the yield strength and corresponding measured values. and hence blunting through nonlinear viscous flow [103]. The relaxation structure which reduced the available free volume increases the relaxation time, and in turn leads to embrittlement as crack-tip stress mitigation through viscous flow becomes less viable [104-106].

\section{Summary and conclusions}

High entropy alloys $\mathrm{CoCrFeMnNiC}_{\mathrm{x}}(x=0,0.5$ and 2 at.\%) with a reduced $\mathrm{Cr}$ content were processed by severe plastic deformation using high pressure torsion. As a result, the microstructure was significantly refined down to nanometer grain size range, and a saturation of grain size was achieved. The interstitial alloying element $\mathrm{C}$ played an important role in the microstructure refinement during HPT and the resulting strengthening of the alloys under investigation:

(i) C interstitials facilitate an increase in dislocation density and grain refinement during high-pressure torsion processing. The grain sizes are reduced to $45 \mathrm{~nm}, 29 \mathrm{~nm}$, and $17 \mathrm{~nm}$ in the alloys with the C content of $0,0.5$, and 2 at.\%, respectively. Meanwhile, the dislocation density increases sharply from $0.57 \times 10^{16} \mathrm{~m}^{-2}$ up to $8.26 \times 10^{16}$ $\mathrm{m}^{-2}$. The deformation mechanisms responsible for microstructure refinement involved deformation twinning and dislocation slip.

(ii) In the as-cast condition the alloy with 2 at.\%C contained carbides at the grain boundaries, enriched with $\mathrm{Cr}$ and $\mathrm{C}$. It appears that the carbides were dissolved during the high-pressure torsion processing. In turn, after three rotations of high-pressure torsion segregation of $\mathrm{C}$ at the nanograin boundaries were detected by XRD. The segregation of $\mathrm{C}$ was suggested to result in finer grains in the C-doped alloys due to a pinning effect.

(iii) The contribution of the conventional strengthening mechanism, Hall-Petch and Taylor relationships, do not explain properly the overall strength of all studied alloys following HPT. The deviation increases with decreasing grain size and increasing the $\mathrm{C}$ content.

(iv) The mechanical behavior can be mainly attributed to the nano-grain size, high dislocation density and $\mathrm{C}$ segregating on the boundaries of nanograins, which lead to very high strength of $2.4 \mathrm{GPa}$ but zero ductility in C2N3 alloy, and to a transition of fracture mechanism from ductile to brittle.

\section{Declaration of Competing Interest}

The authors declare that they have no known competing financial interests or personal relationships that could have appeared to influence the work reported in this paper.

\section{Acknowledgment}

Y.L acknowledges the funding support provided by China Scholarship Council (CSC). N.S. and S.Z. acknowledge the financial support from the Russian Science Foundation (RSF) (grant №181900003). This work was partly carried out with the support of the Karlsruhe Nano Micro Facility (KNMF, www.knmf.kit.edu), a Helmholtz Research Infrastructure at Karlsruhe Institute of Technology (KIT, www.kit.edu). H.H. acknowledges the support by the UC Irvine MRSEC, Center for Complex and Active Materials, under National Science Foundation award DMR-2011967. E.L. is grateful for the Alexander-von-Humboldt Research Award. B. Jóni is acknowledged for performing XRD measurements. D. Chassaing and V. Wollersen are acknowledged for their support in sample preparation.

\section{Supplementary materials}

Supplementary material associated with this article can be found, in the online version, at doi:10.1016/j.mtla.2021.101059.

\section{References}

[1] B. Cantor, I.T.H. Chang, P. Knight, A.J.B. Vincent, Microstructural development in equiatomic multicomponent alloys, Mater. Sci. Eng. A 375-377 (2004) 213-218 https://doi.org/, doi:10.1016/j.msea.2003.10.257.

[2] F. Otto, A. Dlouhý, C. Somsen, H. Bei, G. Eggeler, E.P. George, The influences of temperature and microstructure on the tensile properties of a CoCrFeMnNi high-entropy alloy, Acta Mater. 61 (2013) 5743-5755 https://doi.org/, doi:10.1016/j.actamat.2013.06.018.

[3] F. Otto, N.L. Hanold, E.P. George, Microstructural evolution after thermomechanical processing in an equiatomic, single-phase CoCrFeMnNi high-entropy alloy with special focus on twin boundaries, Intermetallics 54 (2014) 39-48 https://doi.org/, doi:10.1016/j.intermet.2014.05.014. 
[4] G. Laplanche, O. Horst, F. Otto, G. Eggeler, E.P. George, Microstructural evolution of a CoCrFeMnNi high-entropy alloy after swaging and annealing, J. Alloy. Compd. 647 (2015) 548-557 https://doi.org/, doi:10.1016/j.jallcom.2015.05.129.

[5] G. Laplanche, A. Kostka, O.M. Horst, G. Eggeler, E.P. George, Microstructure evolution and critical stress for twinning in the CrMnFeCoNi high-entropy alloy, Acta Mater. 118 (2016) 152-163 https://doi.org/, doi:10.1016/j.actamat.2016.07.038.

[6] W. Abuzaid, H. Sehitoglu, Critical resolved shear stress for slip and twin nucleation in single crystalline FeNiCoCrMn high entropy alloy, Mater. Charact. 129 (2017) 288-299 https://doi.org/, doi:10.1016/j.matchar.2017.05.014.

[7] S.J. Sun, Y.Z. Tian, H.R. Lin, X.G. Dong, Y.H. Wang, Z.J. Zhang, Z.F. Zhang, Enhanced strength and ductility of bulk CoCrFeMnNi high entropy alloy having fully recrystallized ultrafine-grained structure, Mater. Des. 133 (2017) 122-127 https://doi.org/, doi:10.1016/j.matdes.2017.07.054

[8] J.W. Won, S. Lee, S.H. Park, M. Kang, K.R. Lim, C.H. Park, Y.S. Na, Ultrafine-grained CoCrFeMnNi high-entropy alloy produced by cryogenic multipass caliber rolling, J. Alloy. Compd. 742 (2018) 290-295 https://doi.org/, doi:10.1016/j.jallcom.2018.01.313.

[9] X. Ma, J. Chen, X. Wang, Y. Xu, Y. Xue, Microstructure and mechanical properties of cold drawing CoCrFeMnNi high entropy alloy, J. Alloy. Compd. 795 (2019) 45-53 https://doi.org/, doi:10.1016/j.jallcom.2019.04.296.

[10] Z.H. Han, S. Liang, J. Yang, R. Wei, C.J. Zhang, A superior combination of strength-ductility in CoCrFeNiMn high-entropy alloy induced by asymmetric rolling and subsequent annealing treatment, Mater. Charact. 145 (2018) 619-626 https://doi.org/, doi:10.1016/j.matchar.2018.09.029.

[11] Z. Han, W. Ren, J. Yang, Y. Du, R. Wei, C. Zhang, Y. Chen, G. Zhang, The deformation behavior and strain rate sensitivity of ultra-fine grained CoNiFeCrMn high-entropy alloys at temperatures ranging from $77 \mathrm{~K}$ to $573 \mathrm{~K}$, J. Alloys Compd. 791 (2019) 962-970 https://doi.org/, doi:10.1016/j.jallcom.2019.03.373.

[12] A. Gali, E.P. George, Tensile properties of high- and medium-entropy alloys, Intermetallics 39 (2013) 74-78 https://doi.org/, doi:10.1016/j.intermet.2013.03.018

[13] É. Fazakas, V. Zadorozhnyy, L.K. Varga, A. Inoue, D.V. Louzguine-Luzgin, F. Tian, L. Vitos, Experimental and theoretical study of $\mathrm{Ti}_{20} \mathrm{Zr}_{20} \mathrm{Hf}_{20} \mathrm{Nb}_{20} \mathrm{X}_{20}(\mathrm{X}=\mathrm{V}$ or Cr) refractory high-entropy alloys, Int. J. Refract. Met. Hard Mater. 47 (2014) 131-138 https://doi.org/, doi:10.1016/j.ijrmhm.2014.07.009.

[14] Z. Wu, C.M. Parish, H. Bei, Nano-twin mediated plasticity in carbon-containing FeNiCoCrMn high entropy alloys, J. Alloy. Compd. 647 (2015) 815-822 https://doi.org/, doi:10.1016/j.jallcom.2015.05.224.

[15] Z. Li, C.C. Tasan, H. Springer, B. Gault, D. Raabe, Interstitial atoms enable joint twinning and transformation induced plasticity in strong and ductile high-entropy alloys, Sci. Rep. 7 (2017) 1-7 https://doi.org/, doi:10.1038/srep40704.

[16] J. Chen, Z. Yao, X. Wang, Y. Lu, X. Wang, Y. Liu, X. Fan, Effect of $\mathrm{C}$ content on microstructure and tensile properties of as-cast $\mathrm{CoCrFeMnNi}$ high entropy alloy, Mater. Chem. Phys. 210 (2018) 136-145 https://doi.org/, doi:10.1016/j.matchemphys.2017.08.011.

[17] M.V. Klimova, D.G. Shaysultanov, R.S. Chernichenko, V.N. Sanin, N.D. Stepanov, S.V. Zherebtsov, A.N. Belyakov, Recrystallized microstructures and mechanical properties of a C-containing CoCrFeNiMn-type high-entropy alloy, Mater. Sci. Eng. A 740-741 (2019) 201-210 https://doi.org/, doi:10.1016/j.msea.2018.09.113.

[18] M.V. Klimova, A.O. Semenyuk, D.G. Shaysultanov, G.A. Salishchev, S.V. Zherebtsov, N.D. Stepanov, Effect of carbon on cryogenic tensile behavior of CoCrFeMnNi-type high entropy alloys, J. Alloy. Compd. 811 (2019) 152000 https://doi.org/, doi:10.1016/j.jallcom.2019.152000.

[19] J. Su, D. Raabe, Z. Li, Hierarchical microstructure design to tune the mechanical behavior of an interstitial TRIP-TWIP high-entropy alloy, Acta Mater. 163 (2019) 40-54 https://doi.org/, doi:10.1016/j.actamat.2018.10.017.

[20] M.V. Klimova, D.G. Shaysultanov, S.V. Zherebtsov, N.D. Stepanov, Effect of second phase particles on mechanical properties and grain growth in a CoCrFeMnNi high entropy alloy, Mater. Sci. Eng. A 748 (2019) 228-235 https://doi.org/, doi:10.1016/j.msea.2019.01.112.

[21] N.D. Stepanov, N.Y. Yurchenko, M.A. Tikhonovsky, G.A. Salishchev, Effect of carbon content and annealing on structure and hardness of the CoCrFeNiMnbased high entropy alloys, J. Alloy. Compd. 687 (2016) 59-71 https://doi.org/, doi:10.1016/j.jallcom.2016.06.103.

[22] R.Z. Valiev, R.K. Islamgaliev, I.V. Alexandrov, Bulk nanostructured materials from severe plastic deformation, Prog. Mater. Sci. 45 (2000) 103-189 https://doi.org/, doi:10.1016/S0079-6425(99)00007-9.

[23] A.P. Zhilyaev, T.G. Langdon, Using high-pressure torsion for metal processing: fundamentals and applications, Prog. Mater. Sci. 53 (2008) 893-979 https://doi.org/, doi:10.1016/j.pmatsci.2008.03.002.

[24] A. Heczel, M. Kawasaki, J.L. Lábár, J. il Jang, T.G. Langdon, J. Gubicza, Defect structure and hardness in nanocrystalline CoCrFeMnNi high-entropy alloy processed by high-pressure torsion, J. Alloy. Compd. 711 (2017) 143-154 https://doi.org/, doi:10.1016/j.jallcom.2017.03.352.

[25] P.F. Yu, H. Cheng, L.J. Zhang, H. Zhang, Q. Jing, M.Z. Ma, P.K. Liaw, G. Li, R.P. Liu, Effects of high pressure torsion on microstructures and properties of an $\mathrm{A}_{10.1} \mathrm{CoCrFeNi}$ high-entropy alloy, Mater. Sci. Eng. A 655 (2016) 283-291 https://doi.org/, doi:10.1016/j.msea.2015.12.085.

[26] J. Gubicza, P.T. Hung, M. Kawasaki, J.K. Han, Y. Zhao, Y. Xue, J.L. Lábár, Influence of severe plastic deformation on the microstructure and hardness of a CoCrFeNi high-entropy alloy: a comparison with CoCrFeNiMn, Mater. Charact. 154 (2019) 304-314 https://doi.org/, doi:10.1016/j.matchar.2019.06.015.

[27] H. Shahmir, J. He, Z. Lu, M. Kawasaki, T.G. Langdon, Effect of annealing on mechanical properties of a nanocrystalline CoCrFeNiMn high-entropy alloy processed by high-pressure torsion, Mater. Sci. Eng. A 676 (2016) 294-303 https://doi.org/, doi:10.1016/j.msea.2016.08.118.
[28] S. Zherebtsov, N. Stepanov, Y. Ivanisenko, D. Shaysultanov, N. Yurchenko, M. Klimova, G. Salishchev, Evolution of microstructure and mechanical properties of a CoCrFeMnNi high-entropy alloy during high-pressure torsion at room and cryogenic temperatures, Metals 8 (2018) (Basel)https://doi.org/, doi:10.3390/met8020123.

[29] B. Schuh, F. Mendez-Martin, B. Völker, E.P. George, H. Clemens, R. Pippan, A. Hohenwarter, Mechanical properties, microstructure and thermal stability of a nanocrystalline CoCrFeMnNi high-entropy alloy after severe plastic deformation, Acta Mater. 96 (2015) 258-268 https://doi.org/, doi:10.1016/j.actamat.2015.06.025.

[30] Z. Li, Interstitial equiatomic CoCrFeMnNi high-entropy alloys: carbon content, microstructure, and compositional homogeneity effects on deformation behavior, Acta Mater. 164 (2019) 400-412 https://doi.org/, doi:10.1016/j.actamat.2018.10.050.

[31] Z. Wang, I. Baker, Z. Cai, S. Chen, J.D. Poplawsky, W. Guo, The effect of interstitial carbon on the mechanical properties and dislocation substructure evolution in $\mathrm{Fe}_{40.4} \mathrm{Ni}_{11.3} \mathrm{Mn}_{34.8} \mathrm{Al}_{7.5} \mathrm{Cr}_{6}$ high entropy alloys, Acta Mater. 120 (2016) 228-239 https://doi.org/, doi:10.1016/j.actamat.2016.08.072.

[32] Y.Y. Shang, Y. Wu, J.Y. He, X.Y. Zhu, S.F. Liu, H.L. Huang, K. An, Y. Chen, S.H. Jiang, H. Wang, X.J. Liu, Z.P. Lu, Solving the strength-ductility tradeoff in the medium-entropy $\mathrm{NiCoCr}$ alloy via interstitial strengthening of carbon, Intermetallics 106 (2019) 77-87 https://doi.org/, doi:10.1016/j.intermet.2018.12.009.

[33] B.B. Straumal, A.R. Kilmametov, Y. Ivanisenko, A.A. Mazilkin, R.Z. Valiev, N.S. Afonikova, A.S. Gornakova, H. Hahn, Diffusive and displacive phase transitions in Ti-Fe and Ti-Co alloys under high pressure torsion, J. Alloy. Compd. 735 (2018) 2281-2286 https://doi.org/, doi:10.1016/j.jallcom.2017.11.317.

[34] J.A. Beach, M. Wang, P. Bellon, S. Dillon, Y. Ivanisenko, T. Boll, R.S. Averback, Self-organized, size-selection of precipitates during severe plastic deformation of dilute Cu-Nb alloys at low temperatures, Acta Mater. 140 (2017) 217-223 https://doi.org/, doi:10.1016/j.actamat.2017.08.041.

[35] Y. Ivanisenko, W. Lojkowski, R.Z. Valiev, H.J. Fecht, The mechanism of formation of nanostructure and dissolution of cementite in a pearlitic steel during high pressure torsion, Acta Mater. 51 (2003) 5555-5570 https://doi.org/, doi:10.1016/S1359-6454(03)00419-1.

[36] Q.-.J. Li, H. Sheng, E. Ma, Strengthening in multi-principal element alloys with local-chemical-order roughened dislocation pathways, Nat. Commun. 10 (2019) 3563 https://doi.org/, doi:10.1038/s41467-019-11464-7.

[37] O. Ding, Y. Zhang, X. Chen, X. Fu, D. Chen, S. Chen, L. Gu, F. Wei, H. Bei, Y. Gao, M. Wen, J. Li, Z. Zhang, T. Zhu, R.O. Ritchie, Q. Yu, Tuning element distribution, structure and properties by composition in high-entropy alloys, Nature 574 (2019) 223-227 https://doi.org/, doi:10.1038/s41586-019-1617-1.

[38] J. Ding, Q. Yu, M. Asta, R.O. Ritchie, Tunable stacking fault energies by tailoring local chemical order in CrCoNi medium-entropy alloys, Proc. Natl. Acad. Sci. 115 (2018) 8919 LP-8924https://doi.org/, doi:10.1073/pnas.1808660115.

[39] Q. Ding, Y. Zhang, X. Chen, X. Fu, D. Chen, S. Chen, L. Gu, F. Wei, H. Bei, Y. Gao, M. Wen, J. Li, Z. Zhang, T. Zhu, R.O. Ritchie, Q. Yu, Tuning element distribution, structure and properties by composition in high-entropy alloys, Nature 574 (2019) 223-227 https://doi.org/, doi:10.1038/s41586-019-1617-1.

[40] R.Z. Valiev, Y.V. Ivanisenko, E.F. Rauch, B. Baudelet, Structure and deformaton behaviour of Armco iron subjected to severe plastic deformation, Acta Mater. 44 (1996) 4705-4712 https://doi.org/, doi:10.1016/S1359-6454(96)00156-5.

[41] G. Ribárik, J. Gubicza, T. Ungár, Correlation between strength and microstructure of ball-milled Al-Mg alloys determined by X-ray diffraction, Mater. Sci. Eng. A 387389 (2004) 343-347 https://doi.org/, doi:10.1016/j.msea.2004.01.089.

[42] F. Otto, A. Dlouhý, K.G. Pradeep, M. Kuběnová, D. Raabe, G. Eggeler, E.P. George, Decomposition of the single-phase high-entropy alloy CrMnFeCoNi after prolonged anneals at intermediate temperatures, Acta Mater. 112 (2016) 40-52 https://doi.org/, doi:10.1016/j.actamat.2016.04.005.

[43] S.M. Bruemmer, B.W. Arey, L.A. Charlot, Influence of chromium depletion on intergranular stress corrosion cracking of 304 stainless steel, Corrosion 48 (1992) 42-49 https://doi.org/, doi:10.5006/1.3315917.

[44] F.R. Beckitt, B.R. Clark, The shape and mechanism of formation of $\mathrm{M}_{23} \mathrm{C}_{6}$ carbide in austenite, Acta Metall. 15 (1967) 113-129 https://doi.org/, doi:10.1016/0001-6160(67)90159-9.

[45] L.K. Singhal, J.W. Martin, The growth of $\mathrm{M}_{23} \mathrm{C}_{6}$ carbide on incoherent twin boundaries in austenite, Acta Metall. 15 (1967) 1603-1610 https://doi.org/, doi:10.1016/0001-6160(67)90134-4.

[46] H.U. Hong, B.S. Rho, S.W. Nam, Correlation of the $\mathrm{M}_{23} \mathrm{C}_{6}$ precipitation morphology with grain boundary characteristics in austenitic stainless steel, Mater. Sci. Eng. A 318 (2001) 285-292 https://doi.org/, doi:10.1016/S0921-5093(01)01254-0.

[47] T. Thorvaldsson, G.L. Dunlop, Grain boundary Cr-depleted zones in Ti and Nb stabilized austenitic stainless steels, J. Mater. Sci. 18 (1983) 793-803 https://doi.org/, doi:10.1007/BF00745578.

[48] K. Kaneko, T. Fukunaga, K. Yamada, N. Nakada, M. Kikuchi, Z. Saghi, J.S. Barnard, P.A. Midgley, Formation of $\mathrm{M}_{23} \mathrm{C}_{6}$-type precipitates and chromium-depleted zones in austenite stainless steel, Scr. Mater. 65 (2011) 509-512 https://doi.org/, doi:10.1016/j.scriptamat.2011.06.010.

[49] N. Zhu, Y. He, W. Liu, L. Li, S. Huang, J. Vleugels, O. Van der Biest, Modeling of nucleation and growth of $\mathrm{M}_{23} \mathrm{C}_{6}$ carbide in multi-component Fe-based alloy, J. Mater. Sci. Technol. 27 (2011) 725-728 https://doi.org/, doi:10.1016/S1005-0302(11)60133-3.

[50] L. Mújica Roncery, S. Weber, W. Theisen, Nucleation and precipitation kinetics of $\mathrm{M}_{23} \mathrm{C}_{6}$ and $\mathrm{M}_{2} \mathrm{~N}$ in an Fe-Mn-Cr-C-N austenitic matrix and their relationship with the sensitization phenomenon, Acta Mater. 59 (2011) 6275-6286 https://doi.org/, doi:10.1016/j.actamat.2011.06.038. 
[51] G.S. Was, R.M. Kruger, A thermodynamic and kinetic basis for understanding chromium depletion in Ni-Cr-Fe alloys, Acta Metall. 33 (1985) 841-854 https://doi.org/https://doi.org/, doi:10.1016/0001-6160(85)90108-7.

[52] B.R. Pippan, F. Wetscher, M. Hafok, A. Vorhauer, The Limits of Refinement by Severe Plastic Deformation **, (2006) 1046-1056. https://doi.org/ 10.1002/adem.200600133.

[53] Y. Ivanisenko, X. Sauvage, A. Mazilkin, A. Kilmametov, J.A. Beach, B.B. Straumal, Bulk nanocrystalline ferrite stabilized through grain boundary carbon segregation, Adv. Eng. Mater. 20 (2018) 1-6 https://doi.org/, doi:10.1002/adem.201800443.

[54] G. Laplanche, A. Kostka, O.M. Horst, G. Eggeler, E.P. George, Microstructure evolution and critical stress for twinning in the CrMnFeCoNi high-entropy alloy, Acta Mater. 118 (2016) https://doi.org/, doi:10.1016/j.actamat.2016.07.038.

[55] B. Gludovatz, A. Hohenwarter, D. Catoor, E.H. Chang, E.P. George, R.O. Ritchie, A fracture-resistant high-entropy alloy for cryogenic applications, Science 345 (2014) 1153-1158 (80-. )https://doi.org/, doi:10.1126/science.1254581.

[56] B.A. Sun, W.H. Wang, The fracture of bulk metallic glasses, Prog. Mater. Sci. 74 (2015) 211-307 https://doi.org/, doi:10.1016/j.pmatsci.2015.05.002

[57] M.M. Trexler, N.N. Thadhani, Mechanical properties of bulk metallic glasses, Prog. Mater. Sci. 55 (2010) 759-839 https://doi.org/, doi:10.1016/j.pmatsci.2010.04.002.

[58] J.W. Yeh, S.K. Chen, S.J. Lin, J.Y. Gan, T.S. Chin, T.T. Shun, C.H. Tsau, S.Y. Chang, Nanostructured high-entropy alloys with multiple principal elements: novel alloy design concepts and outcomes, Adv. Eng. Mater. 6 (2004) 299-303 https://doi.org/, doi:10.1002/adem.200300567.

[59] Q.H. Tang, Y. Huang, Y.Y. Huang, X.Z. Liao, T.G. Langdon, P.Q. Dai, Hardening of an $\mathrm{A}_{10.3}$ CoCrFeNi high entropy alloy via high-pressure torsion and thermal annealing, Mater. Lett. 151 (2015) 126-129 https://doi.org/, doi:10.1016/j.matlet.2015.03.066.

[60] N. Hansen, R.F. Mehl, New discoveries in deformed metals, Metall. Mater. Trans. A Phys. Metall. Mater. Sci. 32 (2001) 2917-2935 https://doi.org/, doi:10.1007/s11661-001-0167-x.

[61] J.W. Christian, S. Mahajan, Deformation twinning, Prog. Mater. Sci. 39 (1995) 1157 https://doi.org/, doi:10.1016/0079-6425(94)00007-7

[62] N. Stepanov, M. Tikhonovsky, N. Yurchenko, D. Zyabkin, M. Klimova, S. Zherebtsov, A. Efimov, G. Salishchev, Effect of cryo-deformation on structure and properties of CoCrFeNiMn high-entropy alloy, Intermetallics 59 (2015) 8-17 https://doi.org/, doi:10.1016/j.intermet.2014.12.004.

[63] S.V. Zherebtsov, G.S. Dyakonov, A.A. Salem, V.I. Sokolenko, G.A. Salishchev, S.L. Semiatin, Formation of nanostructures in commercial-purity titanium via cryorolling, Acta Mater. 61 (2013) 1167-1178 https://doi.org/, doi:10.1016/j.actamat.2012.10.026.

[64] S. Huang, W. Li, S. Lu, F. Tian, J. Shen, E. Holmström, L. Vitos, Temperature dependent stacking fault energy of FeCrCoNiMn high entropy alloy, Scr. Mater. 108 (2015) 44-47 https://doi.org/, doi:10.1016/j.scriptamat.2015.05.041.

[65] A.J. Zaddach, C. Niu, C.C. Koch, D.L. Irving, Mechanical properties and stacking fault energies of NiFeCrCoMn high-entropy alloy, JOM 65 (2013) 1780-1789 https://doi.org/, doi:10.1007/s11837-013-0771-4

[66] Y. Ikeda, I. Tanaka, J. Neugebauer, F. Körmann, Impact of interstitial C alloying on phase stability and stacking fault energy of the CrMnFeCoNi highentropy alloy, under rev, Phys. Rev. Mater. 113603 (2019) 68-71 https://doi.org/, doi:10.1103/PhysRevMaterials.3.113603.

[67] X. Sauvage, A. Duchaussoy, G. Zaher, Strain induced segregations in severely deformed materials, Mater. Trans. 60 (2019) 1151-1158 https://doi.org/, doi:10.2320/matertrans.MF201919.

[68] X. Sauvage, Y. Ivanisenko, The role of carbon segregation on nanocrystallisation of pearlitic steels processed by severe plastic deformation, J. Mater. Sci. 42 (2007) 1615-1621 https://doi.org/, doi:10.1007/s10853-006-0750-z.

[69] X. Sauvage, G. Wilde, S.V. Divinski, Z. Horita, R.Z. Valiev, Grain boundaries in ultrafine grained materials processed by severe plastic deformation and related phenomena, Mater. Sci. Eng. A 540 (2012) 1-12 https://doi.org/, doi:10.1016/j.msea.2012.01.080.

[70] D. Setman, E. Schafler, E. Korznikova, M.J. Zehetbauer, The presence and nature of vacancy type defects in nanometals detained by severe plastic deformation, Mater. Sci. Eng. A 493 (2008) 116-122 https://doi.org/, doi:10.1016/j.msea.2007.06.093.

[71] A.V. Kazantzis, Z.G. Chen, J.T.M. De Hosson, Deformation mechanism of aluminum-magnesium alloys at elevated temperatures, J. Mater. Sci. 48 (2013) 7399-7408 https://doi.org/, doi:10.1007/s10853-013-7555-7.

[72] M. Fiebig, Y. Tokura, T. Kimura, J.C. Lashley, a P. Ramirez, S. Park, Y.J. Choi, C.L. Zhang, T. Arima, H. Katsura, N. Nagaosa, a V Balatsky, I. a Sergienko, E. Dagotto, M. Mostovoy, a B. Harris, T. Yildirim, a Aharony, G. Lawes, N. Momozawa, Y. Yamaguchi, M. Mita, Y. Nagao, S. Utsumi, M. Abe, Observation of giant diffusivity, Science (2008) 1646-1649 (80-. )https://doi.org/, doi:10.1126/science.1151771.

[73] O. Renk, R. Pippan, Transition from thermally assisted to mechanically driven boundary migration and related apparent activation energies, Scr. Mater. 154 (2018) 212-215 https://doi.org/, doi:10.1016/j.scriptamat.2018.05.052.

[74] O. Renk, P. Ghosh, R. Pippan, Generation of extreme grain aspect ratios in severely deformed tantalum at elevated temperatures, Scr. Mater. 137 (2017) 6063 https://doi.org/, doi:10.1016/j.scriptamat.2017.04.024

[75] Y. Amouyal, S.V. Divinski, L. Klinger, E. Rabkin, Grain boundary diffusion and recrystallization in ultrafine grain copper produced by equal channel angular pressing, Acta Mater. 56 (2008) 5500-5513 https://doi.org/, doi:10.1016/j.actamat.2008.07.029.
[76] D.A. Hughes, N. Hansen, Microstructure and strength of nickel at large strains, Acta Mater. 48 (2000) 2985-3004 https://doi.org/, doi:10.1016/S1359-6454(00)00082-3.

[77] R.A. Jago, N. Hansen, Grain size effects in the deformation of polycrystalline iron, Acta Metall. 34 (1986) 1711-1720 https://doi.org/, doi:10.1016/0001-6160(86)90118-5.

[78] I. Gutierrez-Urrutia, D. Raabe, Multistage strain hardening through dislocation substructure and twinning in a high strength and ductile weightreduced Fe-Mn-Al-C steel, Acta Mater. 60 (2012) 5791-5802 https://doi.org/, doi:10.1016/j.actamat.2012.07.018.

[79] R. Pippan, S. Scheriau, A. Taylor, M. Hafok, A. Hohenwarter, A. Bachmaier, Saturation of fragmentation during severe plastic deformation, Annu. Rev. Mater. Res. 40 (2010) 319-343 https://doi.org/, doi:10.1146/annurev-matsci-070909-104445.

[80] G.B. Rathmayr, R. Pippan, Influence of impurities and deformation temperature on the saturation microstructure and ductility of HPT-deformed nickel, Acta Mater. 59 (2011) 7228-7240 https://doi.org/, doi:10.1016/j.actamat.2011.08.023.

[81] E.O. Hall, The deformation and ageing of mild steel: II characteristics of the lüders deformation, Proc. Phys. Soc. Sect. B 64 (1951) 742-747 https://doi.org/, doi:10.1088/0370-1301/64/9/302.

[82] N.J. Petch, The cleavage strength of polycrystals, J. Iron Steel Inst. 174 (1953) 25-28.

[83] G.I. Taylor, The mechanism of plastic deformation of crystals. part II.-Comparison with observations, Proc. R. Soc. Lon. Ser. A Contain. Pap. Math. Phys. Character 145 (1934) 388-404 https://doi.org/, doi:10.1098/rspa.1934.0107.

[84] C. Zhu, Z.P. Lu, T.G. Nieh, Incipient plasticity and dislocation nucleation of FeCoCrNiMn high-entropy alloy, Acta Mater. 61 (2013) 2993-3001 https://doi.org/, doi:10.1016/j.actamat.2013.01.059.

[85] W.F. Hosford, Mechanical Behavior of Materials, Cambridge University Press, 2005 https://doi.org/, doi:10.1017/cbo9780511810930.

[86] K. Jin, Y.F. Gao, H. Bei, Intrinsic properties and strengthening mechanism of monocrystalline Ni-containing ternary concentrated solid solutions, Mater. Sci. Eng. A 695 (2017) 74-79 https://doi.org/, doi:10.1016/j.msea.2017.04.003.

[87] Z. Wu, Y. Gao, H. Bei, Thermal activation mechanisms and labusch-type strengthening analysis for a family of high-entropy and equiatomic solid-solution alloys, Acta Mater. 120 (2016) 108-119 https://doi.org/, doi:10.1016/j.actamat.2016.08.047.

[88] J. Hu, Y.N. Shi, X. Sauvage, G. Sha, K. Lu, Grain boundary stability governs hardening and softening in extremely fine nanograined metals, Science 355 (2017) 1292 1296 (80-. )https://doi.org/, doi:10.1126/science.aal5166.

[89] M.M. Abramova, N.A. Enikeev, R.Z. Valiev, A. Etienne, B. Radiguet, Y. Ivanisenko, X. Sauvage, Grain boundary segregation induced strengthening of an ultrafinegrained austenitic stainless steel, Mater. Lett. 136 (2014) 349-352 https://doi.org/, doi:10.1016/J.Matlet.2014.07.188.

[90] W. Xu, X.C. Liu, X.Y. Li, K. Lu, Deformation induced grain boundary segregation in nanolaminated Al-Cu alloy, Acta Mater. 182 (2020) 207-214 https://doi.org/, doi:10.1016/j.actamat.2019.10.036.

[91] S.V. Bobylev, N.A. Enikeev, A.G. Sheinerman, R.Z. Valiev, Strength enhancement induced by grain boundary solute segregations in ultrafine-grained alloys, Int. J. Plast. 123 (2019) 133-144 https://doi.org/, doi:10.1016/j.ijplas.2019.07.013.

[92] M.A. Meyers, A. Mishra, D.J. Benson, Mechanical properties of nanocrystalline materials, Prog. Mater. Sci. 51 (2006) 427-556 https://doi.org/, doi:10.1016/j.pmatsci.2005.08.003.

[93] J. Schioøtz, K.W. Jacobsen, A maximum in the strength of nanocrystalline copper, Science 301 (2003) 1357-1359 (80-. )https://doi.org/, doi:10.1126/science. 1086636

[94] S. Takeuchi, The mechanism of the inverse hall-petch relation of nanocrystals, Scr. Mater. 44 (2001) 1483-1487 https://doi.org/, doi:10.1016/S1359-6462(01)00713-8.

[95] A.H. Chokshi, A. Rosen, J. Karch, H. Gleiter, On the validity of the hallpetch relationship in nanocrystalline materials, Scr. Metall. 23 (1989) 1679-1683 https://doi.org/, doi:10.1016/0036-9748(89)90342-6.

[96] L. Zhang, Y. Shibuta, Inverse hall-petch relationship of high-entropy alloy by atomistic simulation, Mater. Lett. 274 (2020) 128024 https://doi.org/, doi:10.1016/j.matlet.2020.128024.

[97] M. Klimova, D. Shaysultanov, A. Semenyuk, S. Zherebtsov, N. Stepanov, Effect of carbon on recrystallised microstructures and properties of CoCrFeMnNi-type high-entropy alloys, J. Alloy. Compd. 851 (2021) 156839 https://doi.org/https://doi.org/, doi:10.1016/j.jallcom.2020.156839.

[98] H. Hahn, P. Mondal, K.A. Padmanabhan, Plastic deformation of nanocrystalline materials, Nanostruct. Mater. 9 (1997) 603-606 https://doi.org/, doi:10.1016/S0965-9773(97)00135-9.

[99] S.J. Sun, Y.Z. Tian, H.R. Lin, H.J. Yang, X.G. Dong, Y.H. Wang, Z.F. Zhang, Transition of twinning behavior in CoCrFeMnNi high entropy alloy with grain refinement, Mater. Sci. Eng. A 712 (2018) 603-607 https://doi.org/, doi:10.1016/j.msea.2017.12.022.

[100] D.T. Pierce, J.A. Jiménez, J. Bentley, D. Raabe, C. Oskay, J.E. Wittig, The influence of manganese content on the stacking fault and austenite $/ \varepsilon$-martensite interfacial energies in Fe-Mn-(Al-Si) steels investigated by experiment and theory, Acta Mater. 68 (2014) 238-253 https://doi.org/, doi:10.1016/j.actamat.2014.01.001.

[101] E.D. Hondros, M.R. Seah, S. Hofmann, P. Lejček, Interfacial and surface microchemistry, in: Physical Metallurgy, Elsevier, 1996, pp. 1201-1289, doi:10.1016/b978-044489875-3/50018-1. https://doi.org/

[102] L.A. Deibler, J.J. Lewandowski, Model experiments to mimic fracture surface features in metallic glasses, Mater. Sci. Eng. A 527 (2010) 2207-2213 https://doi.org/, doi:10.1016/j.msea.2009.10.072. 
[103] P.S. Steif, F. Spaepen, J.W. Hutchinson, Strain localization in amorphous metals, Acta Metall. 30 (1982) 447-455 https://doi.org/, doi:10.1016/0001-6160(82)90225-5.

[104] C.A. Schuh, T.C. Hufnagel, U. Ramamurty, Mechanical behavior of amorphous alloys, Acta Mater. 55 (2007) 4067-4109 https://doi.org/, doi:10.1016/j.actamat.2007.01.052.
[105] D. Suh, R.H. Dauskardt, Effects of open-volume regions on relaxation time scales and fracture behavior of a Zr-Ti-Ni-Cu-Be bulk metallic glass, J. Non. Cryst. Solids 317 (2003) 181-186 https://doi.org/, doi:10.1016/S0022-3093(02)01997-X.

[106] P. Murali, U. Ramamurty, Embrittlement of a bulk metallic glass due to sub-Tg annealing, Acta Mater. 53 (2005) 1467-1478 https://doi.org/, doi:10.1016/j.actamat.2004.11.040. 